\title{
Modeling Municipal Yields with (and without) Bond Insurance
}

\author{
Albert Lee Chun, Ethan Namvar, Xiaoxia Ye, and Fan Yu*
}

Forthcoming Management Science

\footnotetext{
${ }^{*}$ Chun is from the University of Queensland (albertleechun@gmail.com), Namvar is from the University of California, Berkeley (namvar@haas.berkeley.edu), Ye is from University of Bradford (x.ye4@bradford.ac.uk), and Yu is from Claremont McKenna College (fyu $@$ cmc.edu). We wish to thank seminar participants at Claremont McKenna College, McMaster University, the University of New South Wales, the University of Sydney, the University of Technology Sydney, and the University of Toronto for helpful comments. The high performance computing resources provided by the National Supercomputer Centre in Sweden (NSC) at Linköping University are gratefully acknowledged. Finally, the detailed suggestions of the editor, associate editor, and reviewers led to a significant improvement of our paper.
} 


\title{
Modeling Municipal Yields with (and without) Bond Insurance
}

\begin{abstract}
We develop an intensity-based model of municipal yields, making simultaneous use of the CDS premiums of the insurers and both insured and uninsured municipal bond transactions. We estimate the model individually for 61 municipal issuers by exploiting the dramatic decline in credit quality of the bond insurers from July 2007 to June 2008, and decompose the municipal yield spread based on the estimated parameters. The decomposition reveals a dominant role of the liquidity component as well as interactions between liquidity and default similar to those modeled by Chen et al. (2016) for corporate bonds. Towards the end of the sample period, our model also reproduces the "yield inversion" phenomenon documented by Bergstresser et al. (2010).
\end{abstract}




\section{Introduction}

The municipal bond insurance industry, long dominated by the big four of MBIA (Municipal Bond Insurance Association), Ambac (American Municipal Bond Assurance Corp.), FSA (Financial Security Assurance Inc.), and FGIC (Financial Guaranty Insurance Company), suffered a dramatic meltdown during the great recession for insuring structured finance products. While more than half of new municipal bonds were issued with credit enhancement in 2007, the so-called insurance penetration fell to 18 percent in 2008 and only 3.5 percent in 2012. The industry has changed significantly after the financial crisis, with many of the original players either having gone out of business or sidelined by crisis-related legal problems. The new players, which are still trying to establish a reputation, include AGM (Assured Guaranty Municipal Corp.), BAM (Build America Mutual Assurance Company), and National (National Public Finance Guarantee Corp.). These insurers currently carry AA ratings according to the S\&P's and lower ratings like A or Baa according to Moody's. ${ }^{1}$

A great deal can be learned from what happened to the municipal bond insurers, also called monolines, during the financial crisis. Intuitively, the default risk of an insured municipal bond should be a function of the credit quality of both the issuer and the monoline, as well as how closely they are correlated with each other. In the pre-crisis years, the big four carried AAA ratings and rating agencies simply let insured bonds assume the top-notch ratings of the monolines; few people cared about quantifying the risk of insured municipal bonds. During the financial crisis and thereafter, a much greater variation in monoline credit quality has become the norm. It is therefore important, for both rating and valuation purposes, to develop a systematic understanding of the risk of municipal bonds subject to bond insurance. Yet, we continue to see the S\&P's assign an insurer's credit rating to every issue that it insures, which suggests that rating agencies still suffer from a lack of rigorous methodology for evaluating the risk of insured municipal bonds. ${ }^{2}$

\footnotetext{
${ }^{1}$ BAM was created by former FSA employees in July 2012 and has been rated AA by the S\&P's since its inception. AGM was formed when Assured Guaranty acquired FSA in 2009 and has been rated AA since March 2014. Finally, National is owned by MBIA and has been rated AA- since March 2014. For further background of the municipal bond insurance industry, see Wells Fargo (2008), Moldogaziev (2013), and Renick and Bonello (2014).

${ }^{2}$ In principle, it is clearly possible for an insured bond to achieve a higher rating than that of the insurer. For example, assuming that defaults are independent events, a Ba-rated insurer insuring a bond with an intrinsic rating of Ba would lower the probability of bond default to 0.01 percent per year, assuming a default rate of one percent per year for Ba-rated firms (see Exhibit 27 in $\mathrm{Ou}, 2011$ ). This would allow the insured bond to easily clear the threshold for an Aa rating. While the independent default assumption needs to be relaxed, the basic message of the above example comes through even if defaults are correlated.
} 
We begin our analysis by regressing the municipal bond yield on a collection of bond characteristics, some known to proxy for bond liquidity, as well as a dummy variable indicating whether the bond is insured or uninsured; in the case of insured bonds, we also include the CDS premium of the corresponding monoline. Because of the difficulty in gathering accounting and financial information at different levels of municipalities, we use issuer-level fixed effects to control for the average issuer credit quality within our sample period. In another version of the regression, we identify a small number of municipal issuers that are traded in the CDS market and use their CDS premiums as a time-varying proxy for their intrinsic credit quality. Results indicate that the municipal bond yield is positively related to the age of the bond and the CDS premiums of the issuer and the insurer, and negatively related to the insurance dummy.

Based on these intuitive findings, we develop an intensity-based model for municipal yields, taking into consideration insured bonds' protection against credit loss unless both the issuer and the insurer default before a promised bond payment. We model both defaults as doubly stochastic Poisson processes (Lando, 1998) that are independent given their intensities, allowing for the intensities to be correlated. Furthermore, our model accommodates two features that are likely important in fitting municipal yields. First, the municipal bond market is known to be plagued by illiquidity in the form of high transaction costs and dealer markups, and the lack of transparency and dealers' substantial market power have been suggested as the underlying cause (see Harris and Piwowar 2006 and Green et al. 2007). In light of this concern, we estimate an aggregate liquidity factor using all municipal bond transactions following the procedure of Driessen (2005), and allow this factor to drive a direct compensation for the lack of liquidity in municipal yields. Second, we incorporate default and liquidity interactions following He and Milbradt (2014) and Chen et al. (2016). In the context of the municipal bond market, our model accommodates three flavors of default-liquidity interactions. First, illiquidity in the secondary market for municipal bonds can accelerate issuer default through the rollover channel. This, in turn, can increase the financial burden of the insurers. Second, by reducing the value of municipal bonds as collateral, higher issuer default risk can push investors toward more expensive uncollateralized financing, making it more costly to hold municipal bonds. Third, declining monoline credit quality, which adversely affects the value of insured bonds, can in principle play a similar role as issuer default risk in increasing the illiquidity of insured municipal bonds.

To facilitate the estimation of our model, we specify the default intensities of the issuer and the monoline, as well as the liquidity factor, as squared-root diffusions or sums of independent squared-root 
diffusions. This allows for closed-form formulas for monoline CDS premiums and both insured and uninsured municipal bond prices, which produce the measurement equations in an Unscented Kalman Filter (UKF) procedure. ${ }^{3}$ Our estimation proceeds in three steps. In Step 1, we use the entire panel of municipal bond transaction prices to construct short-term and long-term "liquidity spreads," exploiting bond age as an empirical proxy of bond liquidity, and extracting a single liquidity factor from these spreads. In Step 2, we estimate the default intensity for each of the four major monolines using the time-series of their respective CDS term structures. Each of the monoline default intensities is allowed to load on the liquidity factor, which is important because of the aforementioned liquidity-driven default channel for the bond insurers. In Step 3, we select a municipal bond issuer and use the time-series of all of its bond transactions (both insured and uninsured bonds) to estimate its default intensity, along with the differential liquidity discounts of insured and uninsured bonds.

We implement this procedure using data from July 2007 to June 2008 for 61 municipal bond issuers. These issuers are selected because their bonds have relatively continuous trading, thus offering good coverage of pricing data. We focus on 2007-08 because there is very little fluctuation in monoline CDS premiums prior to this period, and these monolines were essentially out of business with extremely high CDS premiums thereafter. ${ }^{4}$ Our results show that the model fits municipal bond prices quite well. The median RMSE in terms of bond yields is around 9 bps for both insured and uninsured bonds, similar to that of Duffee (1999) from fitting the corporate bond yields of 161 firms. For the median issuer, the issuer-specific part of the default intensity is mean-reverting under the physical measure with a long-run mean of $19 \mathrm{bps}$, and is explosive under the risk-neutral measure, implying an upward-sloping default component similar to Duffee's findings for investment-grade corporate issuers. Using the estimated model parameters for the 61 issuers, we decompose the municipal yield spread of a hypothetical bond into default and liquidity components. We find that the liquidity component plays a dominant role in the decomposition, accounting for nearly 60 percent of the yield spread for uninsured bonds and even

\footnotetext{
${ }^{3}$ The UKF is a state of the art estimation technique that has been employed by only a handful of studies in the term structure literature. For instance, Christoffersen et al. (2014) compare the UKF with the more widely used EKF (Extended Kalman Filter) in the context of pricing interest rate swaps, finding the UKF to yield smaller pricing errors and more precise parameter estimates. Filipović and Trolle (2013) use the UKF to decompose the LIBOR-OIS spread into default and nondefault components.

${ }^{4}$ While our sample size for the intensity model estimation is small compared to other studies of municipal yields using panel regressions, it represents the most liquid portion of the municipal bond market. In comparison, Duffee (1999)'s sample of corporate bonds contains 161 firms, where the median firm has an average of 2.5 bond price observations at 92 monthly intervals. This is fairly similar to our sample size (using daily observations).
} 
higher percentages for insured bonds. ${ }^{5}$ We also uncover sizable liquidity-driven default and defaultdriven liquidity components of the municipal yield spread. Interestingly, most of the latter component is attributed to the default risk of the issuer rather than the bond insurer.

The remainder of our paper is organized as follows. Section 2 discusses the related literature and our incremental contribution. Section 3 explains the sources of our data and offers a preliminary analysis of municipal bond yields using panel regressions. Section 4 then presents an intensity-based model of municipal bond pricing with the aforementioned elements of default, liquidity, and insurance. Section 5 contains the results of model estimation and the ensuing municipal yield decomposition. Section 6 conducts several diagnostic tests of the model. We conclude with Section 7.

\section{Related Literature}

The extant literature on municipal bonds has had to contend with several interesting puzzles. First, the long-end of the municipal yield curve appears too high relative to the Treasury yield curve using the marginal tax rate implied at the short-end. Green (1993) resolves this tension by showing that investors can structure a bond portfolio to replicate the pre-tax cash flows of a taxable bond, while at the same time lowering the tax burden on its coupon payments. Because long-term bonds generate most of their cash flows from coupons, this strategy is more effective at long maturities, pulling down taxable yields relative to tax-exempt yields at the long end. ${ }^{6}$ We take as given the relation between after-tax and pre-tax discount factors in Green's model, while treating the marginal tax rate as a constant.

More recently, Bergstresser et al. (2010) document a second puzzle in municipal bonds. Specifically, they use cross-sectional regressions to show that bonds insured by "troubled monolines" have higher yields than uninsured bonds with the same S\&P's issuer credit rating, both during and after the great financial crisis. Moreover, they use Green et al. (2007)'s method to show that municipal bond dealers charge a higher markup on sales to customers for these insured bonds than uninsured bonds. Consistent with their finding, our results from the top 61 municipal bond issuers demonstrate that insured bonds

\footnotetext{
${ }^{5}$ For comparison with the yield spread decomposition for corporate bonds, Longstaff et al. (2005) find liquidity to account for up to 50 percent of the yield spread for bonds rated AAA/AA, while the percentages are lower for bonds rated below AA.

${ }^{6}$ Chalmers (1998) examines the relative yields of Treasury bonds and pre-funded municipal bonds (those backed by Treasury bonds). He finds that these municipal yields display the same tendency to be too high relative to Treasury yields, concluding that default risk does not explain the muni puzzle. Wang et al. (2008) introduce default and liquidity components into Green's model and show that the estimated tax rate is stable across maturity and credit rating.
} 
command a somewhat larger liquidity discount than uninsured bonds, and that this difference results in the so-called "yield inversion" at the end of our sample period, when some of the monolines are nearly bankrupt and the default components of insured and uninsured bonds become more or less equalized. ${ }^{7}$

Our study is similar to Longstaff (2011) in the sense that both exploit term structure modeling techniques to extract information from municipal bond yields. While Longstaff focuses on the very short-end through municipal swaps and infers a time-varying marginal tax rate (as well as its risk premium) embedded in the one-week MSI (Municipal Swap Index) rate, our goal is to estimate from insured and uninsured municipal bonds of all maturities the effects of tax-exemption, default, liquidity, and insurance on municipal bond yields. In the main part of our analysis, we adopt a constant marginal tax rate of 38 percent. $^{8}$ However, we also estimate our model using an alternative tax rate of 50 percent, which is close to Longstaff's time-varying estimate for the 2007-08 period. Our results are qualitatively robust to the choice of the tax rate.

Two other studies employ different methodologies from ours to decompose municipal yields, neither of which examines insured bonds. Schwert (2015) uses regressions to identify the part of the municipal yield spread that co-varies with commonly used bond-level liquidity proxies as the liquidity component of the municipal yield spread. Specifically, a tax-adjusted municipal yield spread is regressed on the first principal component extracted from six liquidity proxies. The estimated coefficient multiplied by this principal component is defined as the liquidity component of the yield spread, and the remainder is then attributed to the default component.

There are several theoretical and empirical concerns with this approach. First, the statutory federal and state income tax rates are used to compute the tax-adjusted yield spread, which ignores the fact that short-term bonds and long-term bonds tend to imply very different marginal tax rates, as demonstrated by Green (1993). Second, if municipal bond liquidity contains a component not sensitive to the six common liquidity measures (hence the first principal component extracted from them), the liquidity (default) component could be underestimated (overestimated). Third, Schwert (2015)'s liquidity component is measured against a "highly liquid" municipal bond, again biasing the liquidity (default) component

\footnotetext{
${ }^{7}$ Bergstresser et al. (2010) investigate a host of explanations for the greater illiquidity of insured bonds, and seem to rule out dumping by mutual funds and insurance companies and the liquidation of Tender Option Bond (TOB) programs. A more satisfactory answer to this question is beyond the scope of our paper.

${ }^{8} \mathrm{~A}$ marginal tax rate of 38 percent can be rationalized by assuming a federal tax rate of 35 percent and a state tax rate of five percent.
} 
down (up). ${ }^{9}$ In our model, both the default intensity and the liquidity discount specifications incorporate constant terms, allowing for flexibility in fitting the level of the default and liquidity components.

Another study that decomposes the municipal yield is Ang et al. (2014), who extract a daily zerocoupon yield curve from all "pre-funded" (hence default-free) municipal bonds and adjust the curve downward for the liquidity difference between pre-funded and regular bonds. This adjustment is made by comparing the yield curve of all regular bonds with that of a subset of regular bonds with liquidity characteristics matching the pre-funded bonds. However, it is unclear whether these two groups of regular bonds have similar municipal credit risk. ${ }^{10}$ Our methodology is not affected by this particular issue because we estimate the model parameters by examining the pricing of an individual issuer's insured and uninsured bonds; we do not pool bonds across different issuers.

Last but not least, He and Milbradt (2014) and Chen et al. (2016) address the important issue of default-liquidity interactions in the pricing of corporate bonds. While He and Milbradt (2014) simply assume that defaulted bonds are less liquid, Chen et al. (2016) endogeneize this assumption by letting bond investors choose between collateralized financing and more expensive uncollateralized financing; as the bond's collateral value decreases with default risk, investors are forced to utilize the more expensive form of financing, which increases the cost of holding corporate bonds. Although our model is reducedform rather than structural, to our knowledge this is the first attempt to estimate the effect of default and liquidity interactions using municipal bond data. The interactions are incorporated through the correlation structure of the default intensity and the liquidity discount. Specifically, we let the data inform us whether it is issuer or insurer credit quality that drives part of the liquidity discount on municipal bonds. At the same time, we let a separately estimated aggregate liquidity factor play a part in the determination of the issuer and insurer default intensities. This structure allows us to maintain a simple one-factor setup throughout the empirical analysis.

\footnotetext{
${ }^{9}$ Consistent with these arguments, both Ang et al. (2014) and our analysis reveal a much larger liquidity component than the default component, while Schwert (2015) reaches the opposite conclusion.

${ }^{10}$ This is a valid concern given the well-documented positive correlation between liquidity and credit risks (Ericsson and Renault, 2006).
} 


\section{Preliminary Analysis}

In this section, we use panel regressions to gain some insights into the various determinants of municipal bond yields, which will be useful for the development of a formal model.

\subsection{Data}

Using CDS data provided by the Markit Group, we plot the five-year premiums of Ambac, FGIC, FSA, and MBIA, the four major municipal bond insurers, from January 2007 to December 2008 in Figure 1. Evidently, the premiums were extremely low and stable prior to July 2007 for all four monolines, but reached dizzying heights in 2008. In particular, FGIC's five-year premium stayed above 5,000 bps for most of the second half of 2008, and Ambac and MBIA's were over 2,000 bps in extended stretches as well. The only exception is FSA, presumably because it was the only major monoline to have reduced its exposure to structured credit products by half between 1995 and 2010 (Moldogaziev, 2013). While we intend to exploit changes in monoline credit quality in our estimation of the effect of bond insurance, variations of this magnitude could necessitate more sophisticated econometric specifications, such as those with regime switches and jumps, that would overly complicate our simple setup. Because of this concern, we limit our sample period to July 2007 to June 2008, where monoline CDS premium variations are substantial but not excessively large.

To select the municipal bonds used in our analysis, we apply several filters to those included in the Mergent Municipal Bond Securities Database. Specifically, we select tax-exempt investment-grade general obligation bonds with semi-annual fixed coupons and no embedded options or sinking fund provisions. In addition, these bonds must be either uninsured or insured by Ambac, FGIC, FSA, or MBIA. ${ }^{11}$ We then match the characteristics of these bonds with corresponding trades in the MSRB (Municipal Securities Rulemaking Board) historical transactions data, which has been used in virtually all muni-related research since mandatory trade reporting by municipal bond dealers began in 1997. Three types of trades are reported in the MSRB data: dealer sales to customers, dealer purchases from customers, and inter-dealer transactions. We focus exclusively on dealer sales to customers because 1)

\footnotetext{
${ }^{11}$ In the 2008 version of the Mergent Municipal Bond Securities Database, there are 2.28 million unique securities, about half of which are insured. Among the insured bonds, approximately 90 percent are insured by the four major monolines. The percentages are: 26 percent (MBIA), 25 percent (FSA), 22 percent (Ambac), and 17 percent (FGIC). Also, a large fraction of the bonds are non-callable (58 percent), non-putable ( $>99$ percent), and free of sinking fund provisions ( $>92$ percent).
} 
these are the majority among the three types of trades, and 2) we want to avoid modeling the bid-ask bounce. This procedure results in a total of 441,103 dealer-to-customer sales on 64,771 bonds from 7,425 unique municipal bond issuers during our one-year sample period.

\subsection{Summary Statistics}

Panel (a) of Table 1 shows that the median bond in our sample is 2.91 years old and has a yield-tomaturity of 3.42 percent, a coupon rate of four percent, a maturity of 4.58 years, and an issue size of $\$ 2.62$ million. The median trade size is $\$ 50,000$. While both the trade size and issue size seem small, they are highly positively skewed with the means much larger than the medians, and the standard deviations in turn much larger than the means. For more detailed summary statistics and sample composition, the reader is referred to existing studies such as Downing and Zhang (2004), Harris and Piwowar (2006), Green et al. (2007), Bergstresser et al. (2010), and Chung et al. (2015), since all of these studies make use of the same MSRB transactions data from which our sample is derived.

Panel (b) of Table 1 then computes the average yield by bond insurer and Moody's bond rating (categories with fewer than 100 observations are omitted). It seems that Ambac, FSA, and MBIA have a different business model from FGIC. While the first three monolines have long maintained their AAA credit rating and are able to "rent out" this top rating to the bonds that they insure, FGIC is content with letting its credit rating fluctuate below the top and insuring lower quality bonds. Comparing the average yields of insured and uninsured bonds, it seems that uninsured bonds have lower yields. This is not the "yield inversion" phenomenon documented by Bergstresser et al. (2010), however. All it means here is that perhaps bond insurance enables an insured bond to barely clear the threshold for the rating that it received, hence its yield is expected to come in at the high end among all bonds with that rating. To examine yield inversion, we should really compare yields on insured and uninsured bonds that share the same issuer, which we will do below in our panel regressions, or at least compare yields on insured and uninsured bonds with the same issuer credit quality, which is what Bergstresser et al. (2010) did when they used S\&P's underlying issuer credit rating. ${ }^{12}$

\footnotetext{
${ }^{12}$ It is still possible that the intrinsic credit quality of issuers of insured bonds is systematically lower than that of issuers of uninsured bonds, even when they share the same intrinsic issuer credit rating. For example, if investors treat all insured Aaa-rated bonds the same and insurers charge the same fee for lending their Aaa rating to Aa-rated issuers, then the lower quality ones among Aa-rated issuers will be more likely to demand bond insurance, because the potential cost savings are greater for them. However, Bergstresser et al. (2015) seem to rule out this possibility using evidence from subsequent rating
} 
The bond rating that we use to generate Panel B comes from Mergent and represents Moody's bond rating at issuance, which may not be an accurate representation of the credit quality of a bond at the time of observation. We have two responses to this concern. First, the estimation of our intensity-based model uses the time-series of bond price observations for a single issuer and does not require bond rating at all. Second, for a small subset of bond issuers, we have a superior proxy for credit quality — the CDS premium of the issuer. This will be useful in the panel regressions below.

\subsection{Regression Analysis of Municipal Bond Yields}

To get a closer look at the determinants of municipal bond yields, we conduct the following panel regression:

$$
y_{i j k t s}=\alpha_{j}+\beta_{s}+d_{i}\left(a_{0}+a_{1} C D S_{k s}\right)+\gamma^{\prime} \text { bond characteristics } i t+\varepsilon_{i j k t s}
$$

where $i, j, k, t$, and $s$ denote bond, issuer, insurer, time of trade, and date of trade, respectively, $d_{i}=1$ for insured bonds and zero otherwise, and $C D S_{k}$ denotes the five-year CDS premium of the monoline $k$ that provides insurance for an insured bond $i$. Among the bond characteristics are coupon rate, maturity, issue size, trade size, and age. We take the logarithm of issue size and trade size because of the large positive skewness documented in Table 1. Of course, we entertain the intuitive conjecture that $a_{0}<0$ and $a_{1}>0$, meaning that bond insurance generally reduces the municipal bond yield, but that the effect is weakened by the insurer's declining credit quality.

Note that the issuer-level fixed effects account for the average issuer credit quality during our (relatively short) sample period, the trading day-level fixed effects incorporate market-wide changes that affect the yields on all municipal bonds, and the bond-level and trade-level characteristics allow for heterogeneity in yields across bonds that share the same issuer. Still, one might be concerned that there is no explanatory variable that captures the time-varying issuer credit quality - to the extent that issuer credit quality is correlated with monoline credit quality, we can see a biased estimate of $a_{1}$. To address this issue, we identify 30 municipal bond issuers that have CDS coverage during 2007-08, and we include their CDS premiums in the enhanced specification below:

$$
y_{i j k t s}=\alpha_{j}+\beta_{s}+d_{i}\left(a_{0}+a_{1} C D S_{k s}\right)+a_{2} C D S_{i s}+\gamma^{\prime} \text { bond characteristics } \text { cht }_{i j}+\varepsilon_{i j k s} .
$$

migrations. 
The trade-off is that the sample size becomes much smaller.

Yet another criticism for yield regressions in general is that a linear specification cannot account for the inherently nonlinear relation between the bond yield and its explanatory variables. We address this concern by creating Aaa-, Aa-, and A-rated subsamples of short-term (maturity less than or equal to five years) and long-term (maturity greater than five years) bonds using Moody's initial bond ratings from Mergent, where the level of credit risk within each subsample is relatively homogeneous. Although some bonds could be mis-classified because their ratings may have changed, the extent of such changes is expected to be small based on Moody's historical rating transitions for municipal bonds (see Exhibit 4 in Tudela et al., 2015).

To our knowledge, there are two existing studies of municipal bond yields and insurance-related effects using the MSRB data and a regression-based methodology. Chung et al. (2015) use a panel regression like ours with the monoline CDS premium, but they include neither uninsured bonds nor issuer-level fixed effects. Therefore, their results are silent on the relation between insured and uninsured bond yields, and could be affected by omitted variables that capture the differences in credit quality across the issuers. Bergstresser et al. (2010) conduct monthly cross-sectional regressions of the bond yield on a "troubled insurer" dummy using groups of both insured and uninsured bonds with the same S\&P's issuer credit rating. They are mainly focused on the differences between insured and uninsured bond yields over time, especially during the financial crisis. The main issue with their approach, of course, is that the credit quality of insured and uninsured bond issuers can be systematically different even within the same rating category.

The results of our regressions are presented in Table 2. Focusing first on the insurance effects, we find that the coefficient on the insurance dummy is mostly negative and significant and ranges from 4 to 11 bps. The coefficient on the monoline five-year CDS premium is mostly positive and significant, though the magnitude is small given the large swing of monoline credit quality during 2007-08. Nonetheless, the size of the coefficient implies a 2 to $12 \mathrm{bps}$ of increase in the municipal bond yield for every 1,000 bps of increase in the monoline five-year CDS premium. In the regression with issuer CDS premiums, we group all bonds together because the sample size is much smaller. This regression shows a close to one-to-one relation between the issuer CDS premium and the municipal bond yield-the coefficient is 0.01 percent, or one $b p$, for every one $b p$ increase in the issuer CDS premium. Meanwhile, the insurance dummy has a coefficient of -0.078 , which is significant at the one-percent level. Interestingly, the effect 
of the monoline CDS premium weakens and is no longer statistically significant. Since the correlations between monoline and issuer CDS premiums are low and insignificant (typically less than 0.2 from Table 3), this could be caused by the reduction in sample size.

Moving on to variables usually considered as indicators of bond liquidity, we find that there is no consistent relation between the bond yield and the issue size of the bond. Trade size, on the other hand, has a consistently negative and significant coefficient among short-term bonds. This fits well with the empirical findings that municipal bond trading costs and dealer markups are a downward-sloping function of trade size (Harris and Piwowar, 2006; Green et al., 2007). However, trade size is not significant when we use a long-term bond sample. In contrast, bond age is positive and significant for short-term bonds, and is positive and significant in the Aaa-rated long-term bond sample, which contains the majority of the long-term bonds. It appears that bond age is the most robust proxy for bond liquidity among the three that we have considered.

Overall, our panel regressions offer many interesting insights into the necessary ingredients for pricing municipal bonds; they demonstrate that issuer default risk, monoline default risk, and liquidity effects all play a role. Yet, a linear specification can only be stretched so far. For example, it would be silly to extrapolate the monoline CDS premium into the $10,000 \mathrm{bp}$ range using the estimate for $a_{1}$ just because that level was reached by FGIC during 2008. Similarly, the one-to-one relation between the municipal bond yield and the issuer CDS premium is likely to break down when the monoline CDS premium is extremely low. While these can all be addressed in ad hoc ways in a regression-based framework, we will now turn to the construction of a formal municipal bond pricing model.

\section{Model}

For pricing municipal bonds, we build on the tradition of reduced-form models with latent factors (e.g., Duffee, 1999). By incorporating default-liquidity interactions, we also extend the work of Longstaff et al. (2005) and Driessen (2005), who treat their liquidity factors as independent of the default factors. Though practically convenient, a downside of reduced-form models is that it could be difficult to decompose the default and liquidity factors further into the pure default, pure liquidity, default-driven liquidity, and liquidity-driven default components articulated by Chen et al. (2016). In order to do that, we first assume the existence of an aggregate liquidity factor that is arguably capturing the effect of pure liquidity. 
With additional assumptions, we can then disentangle default-liquidity interactions within a latent factor model.

\subsection{Aggregate Liquidity Factor}

For now, it suffices to assume the existence of an aggregate municipal bond pure liquidity factor $l_{t}$, which follows a square-root diffusion with parameters $\left(\alpha_{l}, \beta_{l}, \sigma_{l}\right)$ under the risk-neutral measure:

$$
d l_{t}=\left(\alpha_{l}-\beta_{l} l_{t}\right) d t+\sigma_{l} \sqrt{l_{t}} d Z_{l, t}
$$

The detailed procedure for the construction of this factor exploits the relation between bond liquidity and bond age, and is explained in the next section on model estimation.

\subsection{Monoline CDS Pricing}

We assume that the default intensity of the monoline $\lambda_{m, t}$ is given by the following:

$$
\lambda_{m, t}=c_{0}+c_{1} l_{t}+\lambda_{m, t}^{\prime}
$$

with $\lambda_{m, t}^{\prime}$ following a square-root diffusion under the risk-neutral measure with parameters $\left(\alpha_{m}, \beta_{m}, \sigma_{m}\right)$ :

$$
d \lambda_{m, t}^{\prime}=\left(\alpha_{m}-\beta_{m} \lambda_{m, t}^{\prime}\right) d t+\sigma_{m} \sqrt{\lambda_{m, t}^{\prime}} d Z_{m, t}
$$

and $Z_{m, t}$ being independent of $Z_{l, t}$. The parameter $c_{1}$ incorporates the potential correlation between the monoline default intensity and the aggregate liquidity factor. A positive $c_{1}$ can be motivated, for example, by the presence of liquidity-driven default in the municipal bond market. This increase of default risk across the entire municipal bond market then strains the cash flows of the monolines because they insure a large fraction of the bonds. For simplicity, we also assume that the default-free interest rate $r_{t}$ is independent of other random sources in the model, and that the price of a default-free zero-coupon bond with a face value of $\$ 1$ and maturity $t$ is $D(t) .{ }^{13}$ Under these assumptions, the monoline CDS premium

\footnotetext{
${ }^{13}$ Longstaff et al. (2005) argue that this independence assumption greatly simplifies the model, but has little effect on the empirical results.
} 
is derived in Appendix A.

\subsection{Municipal Bond Pricing}

We assume that a municipal issuer with intrinsic default time $\tau_{i}$ and default intensity $\lambda_{i}$ issues zerocoupon bonds with maturity $T$. We first consider insured bonds that are guaranteed by a monoline insurer, so that the promised cash flow will be repaid if either the issuer or the monoline remains solvent before $T$ (assuming zero recovery given default), i.e., the payoff of the bond is:

$$
X_{T}=1_{\left\{\tau_{i}>T \text { or } \tau_{m}>T\right\}}
$$

With municipal bonds, we need to use the after-tax discount factor $M(T)$, which represents the present value of an after-tax dollar at time $T$, to discount the payoffs. Let the marginal tax rate be $\eta$. According to Green (1993, equation 33), $M(T)$ can be obtained through the pre-tax discount factor $D(T)$, which in turns comes from bootstrapping Treasury bond yields:

$$
M(T)=\frac{D(T)}{1-\eta(1-D(T))}
$$

The price of the insured municipal zero-coupon bonds with maturity $T$ is then given as:

$$
\begin{aligned}
\frac{v(T)}{M(T)} & =E\left(1_{\left\{\tau_{i}>T \text { or } \tau_{m}>T\right\}}\right) \\
& =E\left(e^{-\int_{0}^{T} \lambda_{i, s} d s}+e^{-\int_{0}^{T} \lambda_{m, s} d s}-e^{-\int_{0}^{T}\left(\lambda_{i, s}+\lambda_{m, s}\right) d s}\right)
\end{aligned}
$$

As before, the above result assumes the independence between the risk-free rate and the default intensities. In addition, we follow the standard assumption in reduced-form credit risk models — that the default times of the issuer and the monoline are independent given their intensities.

To introduce a liquidity discount, we extend the above pricing relation slightly:

$$
\frac{v(T)}{M(T)}=E\left[e^{-\int_{0}^{T} \gamma_{i, s} d s}\left(e^{-\int_{0}^{T} \lambda_{i, s} d s}+e^{-\int_{0}^{T} \lambda_{m, s} d s}-e^{-\int_{0}^{T}\left(\lambda_{i, s}+\lambda_{m, s}\right) d s}\right)\right]
$$


The default intensity and liquidity discount jointly evolve according to:

$$
\begin{aligned}
& \lambda_{i, t}=c_{4}+c_{5} l_{t}+h_{i, t}, \\
& \gamma_{i, t}=c_{2}+c_{3} l_{t}+c_{6} \lambda_{m, t}^{\prime}+c_{7} h_{i, t},
\end{aligned}
$$

with $h_{i}$ specified as a square-root process under the risk-neutral measure:

$$
d h_{i, t}=\left(\alpha_{i}-\beta_{i} h_{i, t}\right) d t+\sigma_{i} \sqrt{h_{i, t}} d Z_{i, t}
$$

where $Z_{i}$ is independent of $Z_{m}$ driving $\lambda_{m}^{\prime}$ as well as $Z_{l}$ driving the liquidity factor $l$. Together, (9)-(12) complete the specification for the pricing of insured bonds, where the processes $l, \lambda_{m}^{\prime}$, and $h_{i}$ can be estimated sequentially in tractable one-factor settings, and the constant coefficients are estimated for each issuer using its bond transactions. Diagnostics tests in Section 6 will show that this is an adequate description of the comovement of the default intensities and liquidity discounts.

If we further assume that pure liquidity at the issuer level is driven exclusively by the aggregate liquidity factor, then we can further decompose the liquidity discount into pure liquidity and defaultdriven liquidity components:

$$
\begin{aligned}
\gamma_{i, t}^{\text {pure liq }} & =c_{2}+c_{3} l_{t}, \\
\gamma_{i, t}^{\text {def } \rightarrow \text { liq }} & =c_{6} \lambda_{m, t}^{\prime}+c_{7} h_{i, t} .
\end{aligned}
$$

Note that the default-driven liquidity component can arise from the default risk of either the issuer $\left(h_{i}\right)$ or the monoline $\left(\lambda_{m}^{\prime}\right)$. Similarly, the default intensity can be decomposed into pure default and liquiditydriven default components:

$$
\begin{aligned}
& \lambda_{i, t}^{\text {pure def }}=c_{4}+h_{i, t}, \\
& \lambda_{i, t}^{\operatorname{liq} \rightarrow \text { def }}=c_{5} l_{t} .
\end{aligned}
$$

These partitions will be used subsequently to decompose the municipal bond yield spread into its four components.

It should be noted that Bühler and Trapp (2009) made the first attempt to estimate default-liquidity 
interactions in the corporate bond and CDS markets using the reduced-form approach (Badaoui et al., 2013 apply a similar method to sovereign bonds and CDS). When restricted to corporate bonds only, their specification of the default intensity and liquidity discount follows a two-factor model:

$$
\begin{gathered}
\lambda_{i, t}=h_{i, t}+x_{1} g_{i, t}, \\
\gamma_{i, t}=g_{i, t}+x_{2} h_{i, t},
\end{gathered}
$$

where $x_{1}$ and $x_{2}$ are constants and $h$ and $g$ are independent factors. They identify $h$ as the pure default component and $g$ the pure liquidity component, whereas the other two terms capture the interaction between default and liquidity. However, both $g$ and $h$ are latent factors extracted from corporate bond pricing data. Without connecting them explicitly to observables measuring pure default and liquidity effects, it could be $g, h$, or any of their linear combinations that is capturing pure liquidity. We circumvent this problem by identifying the pure liquidity component with the aggregate liquidity factor extracted from municipal bond transactions. ${ }^{14}$

So far, we have focused on the pricing of insured bonds. The pricing of an uninsured municipal zero-coupon bond with zero recovery is given by:

$$
\frac{v(T)}{M(T)}=E\left(e^{-\int_{0}^{T}\left(\lambda_{i, s}+\gamma_{i, s}\right) d s}\right)
$$

which can simply be considered as a special case of (9) with $\lambda_{m, 0}^{\prime}$ set to a very large value. While insured and uninsured bonds share the same issuer default intensity, we allow them to have different liquidity discounts. Specifically, the liquidity discount for uninsured bonds is:

$$
\gamma_{i, t}=c_{2}+c_{3} l_{t}+c_{7} h_{i, t}
$$

which can be further decomposed into pure liquidity $\left(c_{2}+c_{3} l_{t}\right)$ and default-driven liquidity $\left(c_{7} h_{i, t}\right)$ components. Note that the coefficients $\left(c_{2}, c_{3}, c_{7}\right)$ are different from those in (11) for insured bonds. ${ }^{15}$ More-

\footnotetext{
${ }^{14}$ Due to the lack of liquidity in the municipal bond market, we also face the data limitation that there are few days on which two or more bonds of the same issuer would trade (this is true even among the most liquid set of issuers used in our study). This makes it infeasible to estimate two-factor models using daily data on municipal bonds.

${ }^{15}$ When estimation results are presented, we distinguish these coefficients between insured and uninsured bonds by labelling them with "in" and "un" superscripts.
} 
over, we leave out the term proportional to $\lambda_{m}^{\prime}$ because the insurer's credit quality is supposed to be irrelevant to the pricing of uninsured municipal bonds.

For details of the pricing formulas for zero-coupon insured and uninsured bonds, as well as the extension to non-zero recovery rates and coupon-bearing bonds, we refer the reader to Appendix A. In principle, the recovery rate on insured bonds ought to be strictly lower than its counterpart for uninsured bonds because insured bonds would suffer default loss only if both the issuer and the insurer default. These states of the world are probably much rarer and more connected to deep recessions than those in which an average municipal issuer would default. ${ }^{16}$ On the other hand, as bond insurance was rendered moot by the great financial crisis, a convergence should take place between insured and uninsured recovery rates during our sample period. While there are ways to model time-varying recovery rates analytically, we feel that this could be tackled elsewhere given the focus of our study. Therefore, we simply assume a constant recovery rate shared between insured and uninsured bonds, and infer it from bond prices.

\section{Empirical Results}

\subsection{Liquidity Factor}

The first step of our estimation is to construct an aggregate municipal bond liquidity factor. We do this by exploiting the relation between the municipal bond yield and the age of the bond as shown in Table 2 . Our procedure follows Driessen (2005), who identifies a similar relation between bond yield and bond age among corporate bonds. Building upon the regression results, we plot the bond yield against bond age separately for short-term (maturity $\leq 5$ years) and long-term (maturity $>5$ years) bonds. Figure 2 shows that, for both short-term and long-term bonds, bond yield initially increases with age, but then the relation becomes downward-sloping or flat when age is greater than three years (the median bond age is 2.91 in Table 1). The same figure also reveals that bond yield increases with age among the older bonds in our sample.

\footnotetext{
${ }^{16}$ For example, while a significant number of the 80 municipal defaults during 1970-2014 (see Tudela et al., 2015) involved insured bonds, all but two were repaid in full by the monolines. The two exceptions are the sewer bonds of Jefferson County, Alabama insured by XL Capital Assurance Inc. and FGIC, and the Las Vegas Monorail bonds insured by Ambac. Both cases occurred during or shortly after the great financial crisis.
} 
Taking advantage of these more detailed findings, we form four municipal bond portfolios for each day in our sample. Specifically, the first portfolio P1 contains all bonds with maturity $\leq 5$ years and 7 years $\leq$ age $<10$ years, the second portfolio P2 contains all bonds with maturity $>5$ years and 7 years $\leq$ age $<10$ years, the third portfolio P3 contains all bonds with maturity $\leq 5$ years and age $\geq 10$ years, and the fourth portfolio P4 contains all bonds with maturity $>5$ years and age $\geq 10$ years. The first two portfolios are equally-weighted, while the latter two are weighted to match the average duration and rating distribution of the first two portfolios. This way, the average yield differences between P3 and P1 and between $\mathrm{P} 4$ and $\mathrm{P} 2$ reflect only differences in bond liquidity and not interest rate risk or credit risk. ${ }^{17}$ We plot the short-term liquidity spread (P3-P1) and long-term liquidity spread (P4-P2) in Figure 3. We can see that both spreads exhibit an upward trend over the sample period, and that the long-term spread is generally higher than the short-term spread.

Next, we treat these daily "liquidity spreads" as if they were zero-coupon bond yields with maturities set to equal the variable durations of $\mathrm{P} 1$ and $\mathrm{P} 2$, respectively. We then assume that these yields are generated by a one-factor CIR model and proceed to estimate the liquidity factor and its parameters using a standard Kalman Filter, since the mapping from the factor to the zero-coupon bond yield is an affine function. We assume an extended affine market price of risk (Cheridito et al., 2007) so that the liquidity factor process under the $P$-measure is:

$$
d l_{t}=\left(\alpha_{l}^{P}-\beta_{l}^{P} l_{t}\right) d t+\sigma_{l} \sqrt{l_{t}} d Z_{l, t}^{P}
$$

We estimate the liquidity factor parameters as: $\alpha_{l}^{P}=0.004, \beta_{l}^{P}=2.423, \sigma_{l}=0.106, \alpha_{l}=0$, and $\beta_{l}=-0.487$. The physical parameters $\alpha_{l}^{P}$ and $\beta_{l}^{P}$ imply a mean-reverting process under $P$ with a longrun mean of around $17 \mathrm{bps}$. In contrast, the risk-neutral parameters $\alpha_{l}$ and $\beta_{l}$ suggest an explosive process that explains the higher liquidity spread at the long maturity. The time-series of the filtered liquidity factor is represented in Figure 3. Like the liquidity spreads, it also exhibits an upward trend through the sample period, starting around 5 bps in July 2007 and rising above 20 bps in April and June 2008. ${ }^{18}$

\footnotetext{
${ }^{17}$ Under the ideal scenario where these portfolios contain identical bonds (in terms of issuer, maturity, and coupon) except for their age, the average yields of the portfolios should have identical default-related components, including default-driven liquidity. Differencing the average yields then removes these components, leaving only differences in the pure liquidity component.

${ }^{18}$ To further validate this aggregate liquidity factor, we also estimate it over an extended sample period of January 2006 to
} 


\subsection{Monoline Default Intensities}

The second step of our estimation is to extract the default intensities of the four major monolines using their CDS contracts. The CDS pricing formula in Appendix A maps the state variables $\lambda_{m, t}^{\prime}$ and $l_{t}$ into the monoline CDS premium at time $t$. For the value of $l_{t}$, we simply substitute for the filtered liquidity factor from the preceding estimation, assuming that it is observed without error. Therefore, this is effectively a one-factor model of $\lambda_{m, t}^{\prime}$ that can again be estimated using the Kalman Filter. However, the standard KF cannot be used here because the mapping is nonlinear. In this case, one approach is to linearize the so-called "measurement equation" around the long-run mean or the one-period-ahead forecast of the state variable and then apply the standard KF. This "Extended Kalman Filter" (EKF) has been used by Duffee (1999) to estimate an intensity-based model for corporate bond pricing. We, however, use another related approach called the "Unscented Kalman Filter" (UKF), which better addresses nonlinearities in the measurement equation (see Appendix $\mathrm{C}$ for details of the UKF).

We specify the dynamics of $\lambda_{m, t}^{\prime}$ under the physical measure using the same extended affine market price of risk as what we did for the liquidity factor:

$$
d \lambda_{m, t}^{\prime}=\left(\alpha_{m}^{P}-\beta_{m}^{P} \lambda_{m, t}^{\prime}\right) d t+\sigma_{m} \sqrt{\lambda_{m, t}^{\prime}} d Z_{m, t}^{P}
$$

where $Z_{m, t}^{P}$ is independent of $Z_{l, t}^{P}$. This allows us to write down a discretized "transition equation" for the square-root process, also required for the KF estimation. Finally, we conduct the estimation using monoline CDS premiums of the following maturities: six months, one, two, three, four, five, seven, and ten years. We assume that the five-year CDS premium, usually the most highly traded maturity, is observed without error, and use it to infer the value of the state variable $\lambda_{m, t}^{\prime}$. The CDS premiums of other maturities are assumed to contain measurement errors.

Table 4 presents the estimated parameters for the four monolines and Figure 4 compares the actual and model-implied three-year and ten-year CDS premiums. Graphically, we can see that the fitting performance is quite good for Ambac, FSA, and MBIA even though their CDS premiums exhibit very large variations over the sample period. This good performance is also reflected in "VR," or one minus the ratio of the variance of CDS pricing errors to the variance of actual CDS premiums, which is above December 2008. Results show that this factor was on a downward trajectory prior to early 2007 , but began rising rapidly after that, consistent with the evidence based on the Green et al. (2007) markup in Bergstresser et al. (2010). 
0.99 in these three cases. We also compute the "relative RMSE," or the root mean squared CDS pricing error divided by the sample average of actual CDS premiums, which is below 12 percent in these three cases. For comparison purposes, the bid-ask spread in the CDS market is around five to ten percent of the CDS premium in recent years, and this percentage can become even higher for top quality obligors with very low CDS premiums. Therefore, the pricing errors in these three cases are certainly within the margin of tolerance.

We do note the relatively poor fitting performance for FGIC both graphically and as reflected in the lower VR and higher relative RMSE. FGIC has the highest level of CDS premiums among the four monolines, and its short-term CDS premiums (six-month and one-year) exceeded 10,000 bps in June 2008. Therefore, we did not expect great performance from such a simple specification to begin with. In fact, while a one-factor model like ours can match the level of the CDS curve well (e.g., the five-year CDS premium), it has limited ability in matching the slope of the CDS curve. Specifically, the riskneutral drift of $\lambda_{m, t}^{\prime}$ is $\alpha_{m}-\beta_{m} \lambda_{m, t}^{\prime}$, which for positive $\alpha_{m}$ and $\beta_{m}$ will generate a positive slope when the CDS level is low and a negative slope when the CDS level is high. But the relation between the CDS level and slope within our one-factor model is deterministic-explaining deviations from this relation would likely require an additional stochastic factor.

Among the model parameters, we see that $\alpha_{m}^{P}>0$ and $\beta_{m}^{P}<0$ imply an explosive $\lambda_{m, t}^{\prime}$ process under $P$ for all four monolines, which is certainly consistent with their rising CDS levels during our sample period (see Figure 1). Except for FGIC, the risk-neutral parameters $\alpha_{m}$ and $\beta_{m}$ are both positive, with implications for the slope of the CDS curve as we have just discussed. In the case of FGIC, it has $\alpha_{m}<0$ and $\beta_{m}>0$, rendering the drift always negative and suggesting that the model may have trouble simultaneously matching a positive slope when the CDS level is low and a negative slope when the CDS level is high.

For the volatility parameter $\sigma_{m}$, we find similar estimates among Ambac, FSA, and MBIA, and a much larger one for FGIC, again consistent with casual observations of their CDS premiums. We also recall that the parameter $c_{1}$ measures the sensitivity of the monoline default intensity to the aggregate liquidity factor. Our estimate of $c_{1}$ (positive and significant in all cases) is smallest for FSA and largest for FGIC. Lastly, our LGD estimate $w_{m}$ implies a near total loss for Ambac, MBIA, and FGIC, while it is more moderate for FSA. These results are consistent with Ambac, MBIA, and FGIC's identity as "troubled monolines," with much higher expected default loss and sensitivity to market-wide illiquidity 
than the more insulated FSA.

\subsection{Issuer Parameters}

The third and final step of our estimation is to identify the parameters associated with the municipal bond issuers. For each issuer $i$, the parameters to be estimated include $\left(\alpha_{i}, \beta_{i}, \sigma_{i}, \alpha_{i}^{P}, \beta_{i}^{P}\right)$ for $h_{i, t}$, the issuerspecific component of the default intensity; $\left(c_{4}, c_{5}\right)$, the part of the default intensity linear in the liquidity factor; $\left(c_{2}^{i n}, c_{3}^{i n}, c_{6}, c_{7}^{i n}\right)$, the liquidity discount of insured bonds; $\left(c_{2}^{u n}, c_{3}^{u n}, c_{7}^{u n}\right)$, the liquidity discount of uninsured bonds; and $\delta$, the bond recovery rate. ${ }^{19}$ Consistent with previous assumptions, the physical dynamics of $h_{i, t}$ follows:

$$
d h_{i, t}=\left(\alpha_{i}^{P}-\beta_{i}^{P} h_{i, t}\right) d t+\sigma_{i} \sqrt{h_{i, t}} d Z_{i, t}^{P},
$$

where $Z_{i, t}^{P}$ is independent of both $Z_{l, t}^{P}$ and $Z_{m, t}^{P}$.

The municipal bond pricing formulas in Appendix A map $l_{t}, \lambda_{m, t}^{\prime}$, and $h_{i, t}$ into prices of insured and uninsured muni zeros. As before, we substitute out $l_{t}$ and $\lambda_{m, t}^{\prime}$ using their filtered values, leaving this as a one-factor model of $h_{i, t}$ that can be estimated using the UKF. While the UKF procedure does not require regularly-spaced bond price observations, there needs to be enough of them to span the sample period as well as provide enough variation to pin down the large number of model parameters. Our procedure for selecting the issuers is as follows: First, for bonds with multiple dealer sales within the same trading day, we consolidate them into one observation using simple averaging. ${ }^{20}$ Second, we screen for issuers with at least 100 observations that include both insured and uninsured bonds, which are relatively evenly distributed over our sample period. To speed up computation, for cases where there are more than 100 observations, we truncate the data so that only bonds with the highest number of observations are kept. This procedure results in a sample for model estimation that contains 61 issuers.

Table 5 summarizes the estimation results. Because of the large number of issuers, we only present the first quartile, median, third quartile, and mean of the parameter estimates. First, we focus on the general performance of our model as measured by the VR and the relative RMSE. Across the 61 issuers, the median VR is 0.981 for insured bonds and 0.986 for uninsured bonds, showing that the model-

\footnotetext{
${ }^{19}$ Besides these 15 parameters, we need the initial value of the state variable (assuming an initial variance of zero) to start the UKF recursion, and the two variances of pricing errors for insured and uninsured bonds, respectively. Therefore, we have a total of 18 parameters for each issuer.

${ }^{20}$ We have verified that most sales of the same bond on the same day take place at the same price, so that there is little difference between simple averaging and volume-weighted averaging.
} 
generated bond price leaves less than two percent of the variation of the actual bond price unexplained for the median municipal bond issuer. Perhaps more direct for interpretation is the median value of the relative RMSE, which equals 0.467 percent and 0.447 percent for insured and uninsured bonds, respectively. Table 1 shows that the average maturity of the bonds included in our regression analysis is 5.6 years. Assuming a modified duration of five years, the corresponding RMSE in terms of bond yields would be around nine bps for both insured and uninsured bonds. In comparison, the median bond yield RMSE across 161 corporate bond issuers is around 10 bps in Duffee (1999).

Turning our attention to the parameters of the $h_{i, t}$ process, we see that the physical parameters $\alpha_{i}^{P}$ and $\beta_{i}^{P}$ are mostly positive, with the median parameters implying a long-run mean for $h_{i, t}$ of 19 bps $(0.021 / 10.833)$. On the other hand, the risk-neutral parameter $\alpha_{i}$ is uniformly close to zero and $\beta_{i}$ is mostly negative, suggesting that $h_{i, t}$ is explosive under the $Q$ measure. Thus the representative profile for our municipal issuer resembles a highly rated corporate issuer with low and upward-sloping credit spreads (see Section 5 in Duffee, 1999, for relevant discussions). This is not surprising when our 61 issuers include 17 states, 17 cities, and 17 school districts that all have high credit quality.

Our issuer default intensity also includes a constant term $c_{4}$ that averages 50 bps plus $c_{5}$ times the liquidity factor. We see that $c_{5}$ is positively skewed with a mean value of 0.429 , similar in magnitude to the range of $c_{1}$, confirming the importance of liquidity-driven default for both the municipal issuers as well as their insurers.

For the issuer parameters related to the liquidity discount, the pure liquidity part contains a constant term $c_{2}$ that averages $40 \mathrm{bps}$ for both insured and uninsured bonds. Given that the aggregate liquidity factor $l_{t}$ varies only between five and $20 \mathrm{bps}$ during our sample period, the small estimates of $c_{3}$ imply that the pure liquidity part is fairly stable over time. In contrast, the parameter $c_{7}$, which controls the liquidity component driven by the issuer's own default risk, has a median value of above three and shows an extreme positive skewness (for both insured and uninsured bonds). This suggests that default-driven liquidity can rival pure liquidity in size, and is certainly the more volatile of the two. We also find that $c_{6}$, which governs the effect of insurer credit quality on the liquidity of insured bonds, is much smaller in size than $c_{7}$. This is likely due to the fact that the joint default probability of both the issuer and the insurer is not sensitive to the default risk of the insurer when it is so much greater than that of the issuer. ${ }^{21}$

\footnotetext{
${ }^{21}$ During our sample period, municipal issuers' CDS premiums are consistently below $100 \mathrm{bps}$, while troubled insurers' CDS premiums easily exceed $2,500 \mathrm{bps}$.
} 
For the bond recovery rate, we find that it has a median of 0.483 and mean of 0.369 . In comparison, a recent Moody's municipal bond default and recovery study (Tudela et al., 2012) computes a median of 0.80 and mean of 0.65 based on 71 defaults from 1970 to 2011 . It also shows that the recovery rate follows a bimodal distribution with one mode close to zero and the other close to one. There is no doubt that many cases where the recovery rate is exactly one involve insured bonds that are made whole by the monolines. This has the effect of biasing the historical recovery rate upward compared to our bondimplied estimates, which tend to be downward biased due to the coincidence of our sample period with the financial crisis.

The results in Table 5 assume a marginal tax rate of 38 percent. However, Longstaff (2011) estimates the marginal tax rate from municipal swaps that exchange the seven-day MSI rate for a fraction of the LIBOR rate. His estimate is time-varying and averages to about 40-50 percent during the 2007-08 period. Therefore, we repeat the estimation of our model assuming an alternative tax rate of 50 percent. The results are available upon request. As (7) indicates, a higher tax rate $\eta$ corresponds to a higher aftertax discount factor $M(T)$, which by (9) would be compensated by a larger default intensity and liquidity discount. This intuition is borne out by the new parameter estimates, which tend to be uniformly larger in magnitude than the original ones. Nevertheless, our subsequent results on the yield spread decomposition remain qualitatively similar.

\subsection{Decomposing Insured and Uninsured Bond Yields}

Using the estimated model parameters, we now perform a decomposition of the municipal bond yield into default-free, default, insurance (if the bond is insured), and liquidity components. Our methodology is as follows. First, we note that the bond yield depends on the bond maturity and coupon rate, which are generally not the same across issuers. Therefore, we hold fixed a "hypothetical bond" with a maturity of 4.2 years and coupon rate of 5.25 percent, and use the model parameters to compute the municipal yield components. $^{22}$ This way, the decomposition is solely attributed to the (issuer-specific) model parameters and not differences in bond characteristics.

For each issuer and each day in the sample period, given the assumed marginal tax rate and the Treasury discount factors, we use (7) to calculate the yield of a default-free municipal bond, $y_{0}$. We

\footnotetext{
${ }^{22}$ The maturity and coupon rate of the hypothetical bond are the median values across the 61 issuers selected for model estimation.
} 
then switch on the issuer default intensity while keeping the liquidity discount at zero and allowing for no bond insurance. This generates an updated bond yield of $y_{1}$. Then, while still keeping the liquidity discount at zero, we introduce the effect of the bond insurer. We assume that the hypothetical bond is insured by either FSA or MBIA, because we want to examine the effect of monoline credit quality on the yield decomposition, knowing that MBIA's credit quality became much worse than FSA's during our sample period. We update the bond yield to $y_{2}$ after this step. Finally, we turn on the liquidity discount for insured bonds and compute the bond yield in the full model as $y_{3}$. We define the default component as $y_{1}-y_{0}$, the default+insurance component as $y_{2}-y_{0}$, and the liquidity component as $y_{3}-y_{2} \cdot{ }^{23}$ The total of the default+insurance and liquidity components is $y_{3}-y_{0}$, or the total yield spread of the hypothetical insured municipal bond. For the hypothetical uninsured bond, we have the same $y_{0}$ and $y_{1}$ calculation, but turn on the liquidity discount for the uninsured bond after that to obtain its liquidity component.

Table 6 summarizes the sample averages of the yield spread components across the 61 issuers. First, we see that the liquidity component takes up a dominant share of the total yield spread for municipal bonds. For uninsured bonds, the cross-sectional means show that the fraction of yield spread attributed to liquidity is 57 percent $(0.706 /(0.706+0.526))$, with 43 percent attributed to default. For insured bonds, since bond insurance has the effect of sharply reducing the default component (compare the "default" column with the "default+insurance" columns), the share of the yield spread attributed to liquidity is even higher-for the mean components, this is 90 or 95 percent depending on the insurer. ${ }^{24}$ For a similar decompositions of corporate bond yield spreads, Longstaff et al. (2005, Table 4) find that AAA/AArated issuers have an average default component of 0.533 percent out of an average total yield spread of 1.036 percent relative to Treasury yields. While our municipal issuers have a comparable mean default component of 0.526 percent, the liquidity component is much larger. Interestingly, the insured liquidity component appears more tightly distributed cross-sectionally, and larger on average, than the uninsured liquidity component.

Our 61 issuers include 17 states, 17 cities, and 17 school districts (as well as five counties and five state-level public finance entities). Table 6 also summarizes the sample averages of the yield spread

\footnotetext{
${ }^{23}$ We find that the liquidity component is not sensitive to whether FSA or MBIA is used in the second step. In other words, while the choice of the insurer affects $y_{3}$, it does not have a significant effect on $y_{3}-y_{2}$. Generally speaking, the yield spread components are also affected by the order in which we switch on the default intensity and liquidity discount (as well as their own respective components). However, this hardly changes our results.

${ }^{24}$ For example, for the case of MBIA-insured bonds, the liquidity share of the yield spread corresponding to the mean components is $0.987 /(0.987+0.112) \approx 0.90$.
} 
components for each of these three groups. We notice that city-issued (state-issued) bonds have the highest (lowest) default component among the three groups. On the other hand, city-issued bonds have the lowest liquidity component, suggesting that they are the most liquid among the three groups.

Next, we decompose the default and liquidity spreads further into pure default, pure liquidity, liquiditydriven default, and default-driven liquidity components. ${ }^{25}$ The results are presented in Table 7. Across the whole sample, the cross-sectional means of the sample averages show that liquidity-driven default constitutes eight percent $(0.042 / 0.526)$ of the total default component, with the rest being attributed to pure default. For uninsured bonds, default-driven liquidity makes up 30 percent $(0.206 / 0.706)$ of the total liquidity component, while this share increases to 52 percent $(0.516 / 0.987)$ for insured bonds.

It is reassuring that the size and proportion of these default-liquidity interactions are similar to what He and Milbradt (2014) and Chen et al. (2016) present using structural model calibrations. In Table 5 of Chen et al. (2016), for example, we see that the main effect of lower credit rating is a dramatic increase in the size of the pure default component, along with its feedback into liquidity (default-driven liquidity) and then back to default again (liquidity-driven default), while the pure liquidity component remains unchanged. Our municipal yield spread averages 123 bps for uninsured bonds over 2007-08 $(0.526+0.706=1.232)$. If we select on the level of the total yield spread, then the A-rating under the bad economic state seems like an appropriate comparison $(145 \mathrm{bps}){ }^{26}$ The size and percentage of the four components are 55 bps (38\%), 4 bps (3\%), 63 bps (44\%), and 22 bps (15\%), respectively. In our case, they are 48 bps (39\%), 4 bps (3\%), 50 bps (41\%), and 21 bps (17\%), respectively. Although this is only meant as a casual comparison, it suggest that insights from structural models can indeed inform the design of reduced-form models, with similar results that "cross-validate" both approaches.

\subsection{Time Variation of Yield Components}

Examining the sample averages of the yield spread components gives us a good sense of the relative importance of default, liquidity, and the default-liquidity interaction effects. In this subsection, we focus

\footnotetext{
${ }^{25}$ To compute these components, we switch on the pure default, liquidity-driven default, pure liquidity, and default-driven liquidity parts of the default intensity and liquidity discount as described in (13)-(16), in this particular order.

${ }^{26}$ We do not have timely credit ratings on the uninsured municipal bonds. Even if we did, the mapping between rating and default rate can be quite different across municipal and corporate bonds. Moreover, Chen et al. (2016) assume that the bad economic state appears one sixth of the time, while the 2007-09 recession is probably rarer and much more severe. These are some of the reasons why we choose the comparison group based on the total yield spread and not credit rating.
} 
on how these yield spread components change over time.

Figure 5 presents the yield spread components of the hypothetical insured and uninsured bonds, their respectively yield levels, and their yield differences. Daily cross-sectional medians across the 61 issuers are plotted. The left-hand-side (right-hand-side) panels assume MBIA (FSA) as the insurer. We begin our discussion with the case of MBIA. In Panel (a), we see that the default component is generally dominated by the liquidity component in size. At the beginning of our sample period, the default component of the uninsured bond is much larger than the default+insurance component of the insured bond. This is because the CDS premium of MBIA is low during 2007. However, the gap between these two components begins to narrow at the end of 2007 because of MBIA's deteriorating financial conditions. At the end of our sample period, these two components are almost equalized. Panel (a) also shows that the liquidity component of the insured bond is visibly higher than that of the uninsured bond throughout the sample period, although the gap has narrowed toward the end of the sample period. This is probably attributed to a slightly higher sensitivity of the uninsured bond to the liquidity factor. ${ }^{27}$ With these components coming so close to each other, it is not surprising that Panel (e) shows that yield inversion begins to occur near the end of the sample period. In contrast, we do not see any evidence of yield inversion in Panel (f) for the case of FSA because its credit quality did not decline as much as MBIA's. Notably, the default+insurance component of Panel (b) is much lower than that of Panel (a).

Our purpose here is to articulate the conditions under which yield inversion can occur. According to the hypothetical bond example just presented, those conditions have to do with a rapidly declining insurer credit quality as well as liquidity discounts that are slightly greater for insured bonds. While the median estimates in Table 6 are consistent with the liquidity component of insured bonds being about 11 bps higher than that of uninsured bonds, we must point out that these estimates are based on 61 most liquid municipal issuers. Our approach cannot be used to uncover yield inversion in the general population of hundreds of thousands of municipal bonds that are rarely traded. Having said that, Bergstresser et al. (2010, Table 15)'s regression estimate of the additional dealer markup for bonds insured by "troubled monolines" is around 10-15 bps during the first half of 2008, quite similar to the median estimate of the liquidity gap between insured and uninsured bonds in our smaller sample.

We further examine the variation over time of the default and liquidity sub-components in Figure 6. Panel (a) confirms that pure default comprises most of the default component. Unlike the skyrocketing

\footnotetext{
${ }^{27}$ In Table 5, the mean $c_{3}^{u n}$ is 0.251 , greater than the mean $c_{3}^{\text {in }}$ of 0.096 .
} 
monoline CDS premiums, the pure default component follows a stable path and even declines somewhat during 2008. This is consistent with the monolines' woes originating from structured credit products and not municipal bond defaults per se. Meanwhile, liquidity-driven default is a small component that is virtually zero during the first half of the sample, but becomes more significant and volatile during the second half due to the increase of the aggregate liquidity factor. In Panel (b) and (c), we see that the pure liquidity component is also quite stable. For both insured and uninsured bonds, it seems to fluctuate around $60 \mathrm{bps}$. The default-driven liquidity component is slightly larger for insured bonds than uninsured bonds. Both are highly volatile due to the large $c_{7}$ loadings on the issuer-specific part of the default intensity, $h_{i}$.

\section{Diagnostic Tests}

We present several diagnostic tests for our model in this section. First, we check how well the specification of $h_{i, t}$, the issuer-specific part of the issuer default intensity $\lambda_{i, t}$, describes its UKF estimate. Second, we examine several independence assumptions among the state variables $h_{i, t}, \lambda_{m, t}^{\prime}$, and $l_{t}$. Third, we perform numerical tests and a Monte-Carlo exercise to illustrate the robustness of our estimation procedure, particularly with respect to the inference of the recovery rate.

\subsection{Persistence and Homoscedasticity}

We follow Duffee (1999) to construct a normalized one-step-ahead innovation of $\hat{h}_{i, t}$, the UKF estimate of $h_{i, t}$. We denote this standardized innovation as:

$$
\zeta_{i, t}=\frac{\hat{h}_{i, t \mid t}-\hat{h}_{i, t \mid t-\Delta t}}{\sqrt{P_{i, h, t \mid t-\Delta t}}}
$$

where $\hat{h}_{i, t \mid t}, \hat{h}_{i, t \mid t-\Delta t}$, and $P_{i, h, t \mid t-\Delta t}$ are respectively defined in (A14), (A12), and (A13). Duffee suggests that if $h_{i, t}$ is correctly specified (by the assumed square-root process), then $\zeta_{i, t}$ should exhibit homoscedasticity as well as no persistence.

We estimate an AR(3) model jointly across all $i$ for both $\zeta_{i, t}$ and $\left|\zeta_{i, t}\right|$ (we use the absolute value as a 
proxy for volatility):

$$
\begin{aligned}
\zeta_{i, t} & =b_{0}+\sum_{j=1}^{3} b_{j} \zeta_{i, t-j}+e_{i, t}, \\
\left|\zeta_{i, t}\right| & =b_{0}+\sum_{j=1}^{3} b_{j}\left|\zeta_{i, t-j}\right|+b_{4} \hat{h}_{i, t-1}+e_{i, t},
\end{aligned}
$$

where

$$
E\left(e_{i, t}\right)=0 ; E\left(e_{i, t}^{2}\right)=\Omega ; E\left(e_{i, t} e_{j, t}\right)=\rho \Omega, i \neq j ; E\left(e_{i, t} e_{j, t-m}\right)=0, m \neq 0, \forall i, j
$$

The estimation results are shown in Table 8. Similar to Duffee's results, we find evidence of misspecification as the QML estimates of the three $b_{j}$ 's are statistically significant in regression (24). Our estimate of $b_{1}$ is negative, suggesting that the estimated values of the model parameter $\beta_{i}^{P}$ may have overstated the degree of mean reversion in $\hat{h}_{i, t}$. Our point estimate of $\rho$ is 0.19 and significant, but it is much smaller than Duffee's estimate, suggesting that the common component shared among all the $\hat{h}_{i, t}$ 's is probably negligible. As for regression (25), our findings are also largely consistent with Duffee's—on one hand, there are modest GARCH-like effects in $\zeta_{i, t}$ evidenced by the significant estimates of the $b_{j}$ 's; on the other hand, the square-root process sufficiently captures the level-dependent volatility, judging by the absence of a significant coefficient on $\hat{h}_{i, t-1}$.

\subsection{Testing the Independence Assumptions}

Several important assumptions in our model for the dynamics of issuer and monoline default intensities, as summarized in (10) and (4), are the independence between $\lambda_{m, t}^{\prime}$ and $l_{t}, h_{i, t}$ and $l_{t}$, and $\lambda_{m, t}^{\prime}$ and $h_{i, t}$. We therefore compute these correlations using the filtered estimates of the state variables. Since some of the intensities exhibit non-stationary behavior under the physical measure, we take the first difference of the state variables before computing the correlations.

Table 9 provides supportive evidence of the independence assumptions. The last row shows the correlation between $\hat{l}_{t}$ and each individual $\hat{\lambda}_{m, t}^{\prime}$. The absolute values of these correlations are all below 0.21 . The last column shows an average correlation between $\hat{l}_{t}$ and $\hat{h}_{i, t}$ of -0.044 , as well as an average $p$-value for testing the hypothesis of zero correlation of 0.33 . Finally, the average correlation between $\hat{h}_{i, t}$ and each $\hat{\lambda}_{m, t}^{\prime}$ is negative and never exceeds 0.09 in absolute value. These low correlations, along with 
the lack of a large common component among the $\hat{h}_{i, t}$ 's, suggest that our one-factor structure describes the co-movement of the liquidity factor, the four monoline intensities, and the 61 issuer intensities well.

\subsection{Numerical Tests and Monte-Carlo Exercise}

We follow Pan and Singleton (2008)'s procedure to examine the bond price sensitivity to the recovery rate $\delta$, and then conduct a Monte-Carlo simulation exercise regarding the accuracy of model estimation. Figure 7 shows the sensitivity of both insured (FSA) and uninsured coupon (5\%, semiannual) bonds at three maturities (one, four, and eight years) to variations in $\delta$ while holding $(1-\delta) h_{i}$ fixed at the sample median value of 9.4 bps. When computing the bond prices, we set the model parameters to their median values in Table 5. The bond prices clearly depend on $\delta$ and their sensitivity to $\delta$ changes across maturities.

We present the partial derivative of the insured and uninsured bond prices with respect to $\delta$ in Figures 8 and 9. To take into account the effect of fixing $(1-\delta) h_{i}$ in the partial derivative, we consider a variant of the original bond pricing formula defined as:

$$
v^{\prime}(\delta, y)=v\left(\delta, \frac{y}{1-\delta}\right)
$$

where $v$ is given by (A9). The partial derivatives in Figures 8 and 9 are calculated as $\partial v^{\prime} / \partial \delta$. These figures show non-zero partial derivatives over a wide range of values for five parameters, $\sigma_{i}, \alpha_{i}, \beta_{i}$, $(1-\delta) h_{i}$, and $\delta$, suggesting that our identification of the recovery rate is robust.

To further assess the accuracy of the estimation, we perform a Monte-Carlo simulation exercise. Based on the true parameter values of $\alpha_{i}^{P}, \beta_{i}^{P}$, and $\sigma_{i}$ in Table 10, 213 observations of $h_{i}$ (matching the dates in our sample period) are simulated. Given the other true parameters in Table 10, and the values and parameter estimates of $l$ and $\lambda_{m}$ from Section 5.1 and Section 5.2, the prices of six coupon (5\%, semiannual) bonds with maturities of one (Ambac), four (FGIC), eight (FSA), and 10 years (MBIA) for insured bonds, and two and five years for uninsured bonds are computed at every point in time. We then add measurement noise consistent with the estimated level to these bond prices and estimate the model parameters using the UKF procedure. In total, we perform this simulation and estimation 500 times. The results are summarized in Table 10. Except for $\alpha_{i}^{P}$ and $\beta_{i}^{P}$, all the other parameters are estimated with very high precision, including the recovery rate $\delta$. This imprecision is somewhat expected given the 
well documented difficulty in estimating the mean reversion parameter under the $P$ measure. ${ }^{28}$ However, this drawback has little effect on accurately identifying the other parameters in the model. Table 10 also shows that the latent state variable $h_{i}$ is estimated quite precisely; across the 500 simulations, the mean RMSE of the state variable is under four bps and the mean relative RMSE is around 11 percent, while the median values are smaller. Therefore, we believe that our model parameters and state variable have been estimated reliably in Table 5 .

\section{Concluding Remarks}

We construct an intensity-based model of municipal yields, similar to that of Duffee (1999) for pricing corporate bonds, but with features unique to the municipal bond market. One important feature is that a significant percentage of municipal bonds carry bond insurance, and their pricing is likely influenced by the credit quality of the insurer besides that of the municipal issuer. Another important feature is that municipal bonds trade infrequently, and their pricing is probably subject to substantial liquidity discounts as well as feedback effects between default and liquidity.

We estimate the model in stages, first constructing an aggregate liquidity factor and estimating the default intensities of bond insurers from their CDS curves, and then disentangling issuer default risk, bond recovery rate, liquidity discounts, and default-liquidity interactions using insured and uninsured bond transactions of 61 issuers from July 2007 to June 2008. We find that the model generates pricing errors similar to that of Duffee (1999) for 161 issuers of corporate bonds, with a median RMSE of nine bps. We use the model to decompose the municipal bond yield into default-free, default (with or without bond insurance), and liquidity components. Results indicate that the average liquidity component accounts for close to 60 percent of the total uninsured municipal yield spread, and that the median liquidity component is about 11 bps higher for insured bonds than uninsured bonds. The latter finding can generate "yield inversion" towards the end of our sample period, when bond insurers' credit quality worsened. Further decomposition of the default and liquidity components shows substantial liquiditydriven default and default-driven liquidity effects similar in size to those predicted by Chen et al. (2016) using a structural approach.

These findings suggest that an intensity-based model like ours can be used to extract meaningful

\footnotetext{
${ }^{28}$ For example, see Duffee and Stanton (2012); Yu (2012).
} 
information about default probabilities, bond recoveries, and liquidity premiums from municipal bond prices. While many aspects of our model can be improved, we hope that it can serve as a useful tool and benchmark for academic researchers and industry practitioners interested in assessing the risks of municipal bonds. 


\section{Appendices}

\section{A Pricing Formulas}

We first present the CDS pricing formula for the monolines. With payment dates denoted as $0<t_{1}<$ $t_{2}<\cdots<t_{n}$, the default time $\tau_{m}$, and the CDS premium $c_{m}$, the present value of future quarterly CDS premium payments is:

$$
\frac{c_{m}}{4} E\left(\sum_{i=1}^{n} e^{-\int_{0}^{t_{i}} r_{s} d s} 1_{\left\{\tau_{m}>t_{i}\right\}}\right)=\frac{c_{m}}{4} \sum_{i=1}^{n} D\left(t_{i}\right) E\left(e^{-\int_{0}^{t_{i}} \lambda_{m, s} d s}\right)=\frac{c_{m}}{4} \sum_{i=1}^{n} D\left(t_{i}\right) \Phi_{m}\left(t_{i}\right)
$$

where

$$
\begin{aligned}
\Phi_{m}(t) & =A_{m}(t) A_{l}\left(t ; c_{1}\right) \exp \left(-c_{0} t+B_{m}(t) \lambda_{m, 0}^{\prime}+B_{l}\left(t ; c_{1}\right) c_{1} l_{0}\right) \\
A_{m}(t) & =A\left(t ; \alpha_{m}, \beta_{m}, \sigma_{m}, 1\right) \\
B_{m}(t) & =B\left(t ; \beta_{m}, \sigma_{m}, 1\right) \\
A_{l}(t ; z) & =A\left(t ; \alpha_{l}, \beta_{l}, \sigma_{l}, z\right) \\
B_{l}(t ; z) & =B\left(t ; \beta_{l}, \sigma_{l}, z\right)
\end{aligned}
$$

and the functions $A$ and $B$ are defined in Appendix B.

On the other hand, the present value of the CDS seller's protection payment is:

$$
E\left(e^{-\int_{0}^{\tau_{m}} r_{s} d s} 1_{\left\{\tau_{m} \leq t_{n}\right\}} W_{m, \tau_{m}}\right)
$$

where

$$
W_{m, \tau_{m}}=w_{m}-c_{m}\left(t-\frac{\left\llcorner 4 \tau_{m}\right\lrcorner}{4}\right)
$$

In this expression, $w_{m}$ is a model parameter to be estimated, reflecting the LGD of the bonds underlying the monoline CDS contracts. The term being subtracted from $w_{m}$ reflects the accrued CDS premium from the previous payment date to the time of default, with $\left\llcorner 4 \tau_{m}\right\lrcorner$ denoting the largest integer smaller 
than $4 \tau_{m}$. We can rewrite (A2) as:

$$
\int_{0}^{t_{n}} D(t) \Psi_{m}(t) W_{m, t} d t
$$

where

$$
\begin{aligned}
\Psi_{m}(t) & =\left[c_{0} A_{m}(t) A_{l}\left(t ; c_{1}\right)+A_{m}(t)\left(G_{l}\left(t ; c_{1}\right)+H_{l}\left(t ; c_{1}\right) c_{1} l_{0}\right)\right. \\
& \left.+A_{l}\left(t ; c_{1}\right)\left(G_{m}(t)+H_{m}(t) \lambda_{m, 0}^{\prime}\right)\right] \exp \left(-c_{0} t+B_{m}(t) \lambda_{m, 0}^{\prime}+B_{l}\left(t ; c_{1}\right) c_{1} l_{0}\right), \\
G_{m}(t) & =G\left(t ; \alpha_{m}, \beta_{m}, \sigma_{m}, 1\right) \\
H_{m}(t) & =H\left(t ; \alpha_{m}, \beta_{m}, \sigma_{m}, 1\right) \\
G_{l}(t ; z) & =G\left(t ; \alpha_{l}, \beta_{l}, \sigma_{l}, z\right) \\
H_{l}(t ; z) & =H\left(t ; \alpha_{l}, \beta_{l}, \sigma_{l}, z\right)
\end{aligned}
$$

and the functions $G$ and $H$ are defined in Appendix B. Note that we have relied on the independence between $l_{t}$ and $\lambda_{m, t}^{\prime}$ when deriving the expressions for $\Phi_{m}(t)$ and $\Psi_{m}(t)$.

Equating (A1) and (A3), we can solve for the CDS premium as a function of the current value of the factors, $\lambda_{m, 0}^{\prime}$ and $l_{0}$. In general, if we choose a finer set of grid points, $0=s_{0}<s_{1}<\cdots<s_{m}=t_{n}, \Delta t$ apart from each other, to approximate the integral in (A3), the CDS premium will be:

$$
c_{m}=\frac{w_{m} \Delta t \sum_{j=1}^{m} D\left(s_{j}\right) \Psi_{m}\left(s_{j}\right)}{\frac{1}{4} \sum_{i=1}^{n} D\left(t_{i}\right) \Phi_{m}\left(t_{i}\right)+\Delta t \sum_{j=1}^{m} D\left(s_{j}\right) \Psi_{m}\left(s_{j}\right)\left(s_{j}-\frac{\left\llcorner 4 s_{j}\right\lrcorner}{4}\right)} .
$$

If we follow Berndt et al. (2008) to use the midpoints between the quarterly payments, i.e., $s_{i}=\left(t_{i-1}+t_{i}\right) / 2$, $i=1,2, \ldots, n$, we have:

$$
c_{m}=\frac{w_{m} \sum_{i=1}^{n} D\left(s_{i}\right) \Psi_{m}\left(s_{i}\right)}{\sum_{i=1}^{n} D\left(t_{i}\right) \Phi_{m}\left(t_{i}\right)+\frac{1}{8} \sum_{i=1}^{n} D\left(s_{i}\right) \Psi_{m}\left(s_{i}\right)} .
$$

In practice, this approximation to the integral is quite accurate and we use it in the rest of our empirical analysis.

We next derive the municipal bond pricing formulas. For insured bonds, (9) can be evaluated by 
noting that:

$$
\begin{aligned}
& E\left(e^{-\int_{0}^{T}\left(\lambda_{i, s}+\gamma_{i, s}\right) d s}\right)=A_{l}\left(T ; c_{3}+c_{5}\right) A_{m}\left(T ; c_{6}\right) A_{i}\left(T ; 1+c_{7}\right) \times \\
& \exp \left[-\left(c_{2}+c_{4}\right) T+B_{l}\left(T ; c_{3}+c_{5}\right)\left(c_{3}+c_{5}\right) l_{0}+B_{m}\left(T ; c_{6}\right) c_{6} \lambda_{m, 0}^{\prime}+B_{i}\left(T ; 1+c_{7}\right)\left(1+c_{7}\right) h_{i, 0}\right], \\
& E\left(e^{-\int_{0}^{T}\left(\lambda_{m, s}+\gamma_{i, s}\right) d s}\right)=A_{l}\left(T ; c_{1}+c_{3}\right) A_{m}\left(T ; 1+c_{6}\right) A_{i}\left(T ; c_{7}\right) \times \\
& \exp \left[-\left(c_{0}+c_{2}\right) T+B_{l}\left(T ; c_{1}+c_{3}\right)\left(c_{1}+c_{3}\right) l_{0}+B_{m}\left(T ; 1+c_{6}\right)\left(1+c_{6}\right) \lambda_{m, 0}^{\prime}+B_{i}\left(T ; c_{7}\right) c_{7} h_{i, 0}\right], \\
& E\left(e^{-\int_{0}^{T}\left(\lambda_{i, s}+\lambda_{m, s}+\gamma_{i, s}\right) d s}\right)=A_{l}\left(T ; c_{1}+c_{3}+c_{5}\right) A_{m}\left(T ; 1+c_{6}\right) A_{i}\left(T ; 1+c_{7}\right) \times \\
& \exp \left[-\left(c_{0}+c_{2}+c_{4}\right) T+B_{l}\left(T ; c_{1}+c_{3}+c_{5}\right)\left(c_{1}+c_{3}+c_{5}\right) l_{0}+B_{m}\left(T ; 1+c_{6}\right)\left(1+c_{6}\right) \lambda_{m, 0}^{\prime}+\right. \\
& \left.B_{i}\left(T ; 1+c_{7}\right)\left(1+c_{7}\right) h_{i, 0}\right] .
\end{aligned}
$$

We now extend the notation above to denote the price of a municipal bond with maturity $T$, coupon rate $c$, and recovery rate $\delta$ as $v(T, c, \delta)$. Here, it is assumed that for each unit of promised payment at $t$ (including both principal and coupon payments), a fraction $\delta$ units are paid at $t$ when default occurs before $t$. This is the well-known "recovery of Treasury" (RT) assumption introduced in Jarrow and Turnbull (1995) (refer to the appendix of Duffee (1999) for a similar treatment of corporate bonds). By the absence of arbitrage, we have:

$$
v(T, c, \delta)=\sum_{i=1}^{n} v\left(T_{i}, 0, \delta\right) c+v(T, 0, \delta)
$$

where $T_{i}, i=1,2, \ldots, n$ are the coupon dates. Under the RT assumption, we can write the zero-coupon muni bond price (with recovery rate $\delta$ ) as:

$$
v(T, 0, \delta)=\delta M(T) E\left(e^{-\int_{0}^{T} \lambda_{i, s} d s}\right)+(1-\delta) v(T),
$$

where $M(T)$ is given by (7), $v(T)$ by (9), and

$$
\begin{aligned}
E\left(e^{-\int_{0}^{T} \lambda_{i, s} d s}\right) & =A_{l}\left(T ; c_{3}\right) A_{m}\left(T ; c_{6}\right) A_{i}\left(T ; c_{7}\right) \times \\
& \exp \left[-c_{2} T+B_{l}\left(T ; c_{3}\right) c_{3} l_{0}+B_{m}\left(T ; c_{6}\right) c_{6} \lambda_{m, 0}^{\prime}+B_{i}\left(T ; c_{7}\right) c_{7} h_{i, 0}\right]
\end{aligned}
$$


Since both terms in (A10) contain a liquidity discount, we have followed the assumption in Longstaff et al. (2005) to apply the liquidity discount to the entire bond price. This completes the specification of insured municipal coupon bond pricing. For uninsured municipal bond pricing, the same set of formulas can be used, but we need to set $\lambda_{m, 0}^{\prime}$ to a very large value and let $c_{6}=0$.

\section{B Definition of Functions $A, B, G$, and $H$}

Following Longstaff et al. (2005), for a default time $\tau$ with intensity $\lambda$ described by a square-root process,

$$
d \lambda_{t}=\left(\alpha-\beta \lambda_{t}\right) d t+\sigma \sqrt{\lambda_{t}} d Z_{t}
$$

the expectations below, which are useful in the computation of CDS premiums and municipal bond prices, can be evaluated as:

$$
\begin{aligned}
E\left(e^{-\int_{0}^{t} c \lambda_{s} d s}\right) & =A(t ; \alpha, \beta, \sigma, c) e^{B(t ; \beta, \sigma, c) c \lambda_{0}} \\
E\left(c \lambda_{t} e^{-\int_{0}^{t} c \lambda_{s} d s}\right) & =\left(G(t ; \alpha, \beta, \sigma, c)+H(t ; \alpha, \beta, \sigma, c) c \lambda_{0}\right) e^{B(t ; \beta, \sigma, c) c \lambda_{0}}
\end{aligned}
$$

When $\beta^{2}+2 c \sigma^{2}>0$,

$$
\begin{aligned}
A(t ; \alpha, \beta, \sigma, c) & =e^{\frac{\alpha(\beta+\phi)}{\sigma^{2}} t}\left(\frac{1-\kappa}{1-\kappa e^{\phi t}}\right)^{\frac{2 \alpha}{\sigma^{2}}} \\
B(t ; \beta, \sigma, c) & =\frac{\beta-\phi}{c \sigma^{2}}+\frac{2 \phi}{c \sigma^{2}\left(1-\kappa e^{\phi t}\right)} \\
G(t ; \alpha, \beta, \sigma, c) & =\frac{\alpha c}{\phi}\left(e^{\phi t}-1\right) e^{\frac{\alpha(\beta+\phi)}{\sigma^{2}} t}\left(\frac{1-\kappa}{1-\kappa e^{\phi t}}\right)^{\frac{2 \alpha}{\sigma^{2}}+1} \\
H(t ; \alpha, \beta, \sigma, c) & =e^{\frac{\alpha(\beta+\phi)+\phi \sigma^{2}}{\sigma^{2}} t}\left(\frac{1-\kappa}{1-\kappa e^{\phi t}}\right)^{\frac{2 \alpha}{\sigma^{2}}+2}
\end{aligned}
$$

and

$$
\phi=\sqrt{2 c \sigma^{2}+\beta^{2}}, \kappa=\frac{\beta+\phi}{\beta-\phi} .
$$

Note that $H(t)=-A(t) B^{\prime}(t)$ and $G(t)=-A^{\prime}(t)$. 
When $\beta^{2}+2 c \sigma^{2}<0$,

$$
\begin{aligned}
& A(t ; \alpha, \beta, \sigma, c)=e^{\frac{\alpha \beta}{\sigma^{2}} t}\left(\frac{\bar{\phi}}{|\varphi(t)|}\right)^{\frac{2 \alpha}{\sigma^{2}}}, B(t ; \beta, \sigma, c)=-\frac{2 \tan \left(\frac{\bar{\phi} t}{2}\right)}{\bar{\phi}+\beta \tan \left(\frac{\bar{\phi} t}{2}\right)} \\
& G(t ; \alpha, \beta, \sigma, c)=-\frac{\alpha \bar{\phi}^{\frac{2 \alpha}{\sigma^{2}}} e^{\frac{\alpha \beta}{\sigma^{2}} t}}{\sigma^{2}|\varphi(t)|\left(1+\frac{2 \alpha}{\sigma^{2}}\right)} \\
& \left\{\beta|\varphi(t)|+\bar{\phi} \operatorname{signum}(\varphi(t))\left[\bar{\phi} \sin \left(\frac{\bar{\phi} t}{2}\right)-\beta \cos \left(\frac{\bar{\phi} t}{2}\right)\right]\right\}, \\
& H(t ; \alpha, \beta, \sigma, c)=e^{\frac{\alpha \beta}{\sigma^{2}} t}\left(\frac{\bar{\phi}}{|\varphi(t)|}\right)^{\frac{2 \alpha}{\sigma^{2}}} \frac{\tan ^{2}\left(\frac{\bar{\phi} t}{2}\right)+1}{\left(1+\frac{\beta \tan \left(\frac{\bar{\phi} t}{2}\right)}{\bar{\phi}}\right)^{2}}
\end{aligned}
$$

where $\varphi(t)=\beta \sin \left(\frac{\bar{\phi} t}{2}\right)+\bar{\phi} \cos \left(\frac{\bar{\phi} t}{2}\right), \bar{\phi}=\sqrt{-2 c \sigma^{2}-\beta^{2}}$, and

$$
\operatorname{signum}(z)=\left\{\begin{array}{l}
\frac{z}{|z|} \text { if } z \neq 0 \\
0 \text { if } z=0
\end{array} .\right.
$$

\section{Unscented Kalman Filter}

The Unscented Kalman Filter (UKF) is a well-developed technique, widely applied in state estimation, neural networks, and nonlinear dynamic systems (see, e.g., Haykin et al., 2001 and Simon, 2006). Since the measurement equations in the state space formulation are nonlinear (for both CDS premiums and municipal bond prices) in this paper, the UKF is the natural choice for our estimation procedure. The state space (one-dimensional transition and $m$-dimensional measurements) is given by the following system:

\section{Transition equation}

$$
X_{t}=\mathscr{T} X_{t-\Delta t}+\Theta+\sqrt{\mathbf{V}_{t}} e_{t}, \quad e_{t} \sim N(0,1),
$$

where $X_{t}$ represents either $\lambda_{m, t}^{\prime}$ or $h_{t}$ depending on estimating the CDS model or the municipal bond model, $\mathscr{T}$ and $\Theta$ are given by discretizing $\lambda_{m}^{\prime}$ or $h_{i}$, and $\mathbf{V}_{t}$ is given by matching the variance of the innovation term in the discretized state dynamic. 


\section{Measurement equation}

$$
y_{t}=\mathscr{G}\left(X_{t}\right)+\zeta_{t}, \quad \zeta_{t} \sim N\left(\mathbf{0}_{m \times 1}, \mathscr{S}_{m \times m}\right)
$$

where $\mathscr{G}(\cdot)$ is a nonlinear function of the state variable, giving the CDS premiums or the municipal bond prices, $\zeta_{t}$ is the pricing error, and $\mathscr{S}$ is a diagonal covariance matrix with positive and distinct diagonal elements.

The essence of the UKF (Chow et al., 2007) used in this paper can be summarized briefly as follows. For each measurement time $t$, a set of deterministically selected points, termed sigma points, are used to approximate the distribution of the current state estimated at time $t$ using a normal distribution with a mean vector $X_{t \mid t-\Delta t}$ and a covariance matrix that is a function of the state covariance matrix, $P_{X, t-\Delta t} \mid t-\Delta t$, and the conditional covariance $\mathbf{V}_{t} \cdot{ }^{29}$ Sigma points are specifically selected to capture the dispersion around $X_{t \mid t-\Delta t}$, and are then projected using the measurement function $\mathscr{G}(\cdot)$, weighted, and then used to update the estimates in conjunction with the newly observed measurements at time $t$ to obtain $X_{t \mid t}$ and $P_{X, t \mid t}$.

Next, we outline the detailed UKF algorithm:

1. Initialization: ${ }^{30}$

$$
\begin{aligned}
X_{0 \mid 0} & =\text { Constant }, \\
P_{0 \mid 0} & =0 .
\end{aligned}
$$

2. Ex-ante predictions of the state:

$$
\begin{aligned}
X_{t \mid t-\Delta t} & =\mathscr{T} X_{t-\Delta t \mid t-\Delta t}+\Theta, \\
P_{X, t \mid t-\Delta t} & =\mathscr{T} P_{X, t-\Delta t \mid t-\Delta t} \mathscr{T}^{\prime}+\mathbf{V}_{t} .
\end{aligned}
$$

\footnotetext{
${ }^{29}$ In the typical UKF setting, both transition and measurement equations are nonlinear. Hence, to compute the ex-ante predictions of the state variables' mean and variance, sigma points are needed to approximate the distribution of the previous state estimates. However, in our paper, the transition equations are linear. Therefore, we can directly compute the ex-ante predictions as in the standard Kalman Filter, without needing sigma points at this stage.

${ }^{30}$ Normally, the UKF is initialized at the unconditional mean and variance of the state variable. However, in the current case, the state variable is typically a non-stationary (explosive) process with no finite unconditional mean and variance. So in our case, we initialize the UKF at a constant parameter to be estimated with zero variance. This essentially assumes that by searching for the starting point of the UKF using the MLE criterion, we know exactly where the UKF starts.
} 
3. Selecting sigma points:

Given the ex-ante prediction of the state variable $X_{t \mid t-\Delta t}$, three sigma points are selected as follows:

$$
\chi_{t \mid t-\Delta t}=\left[\begin{array}{lll}
\chi_{0, t-\Delta t} & \chi_{+, t-\Delta t} & \chi_{-, t-\Delta t}
\end{array}\right]
$$

where

$$
\begin{aligned}
& \chi_{0, t-\Delta t}=X_{t \mid t-\Delta t}, \\
& \chi_{+, t-\Delta t}=X_{t \mid t-\Delta t}+\sqrt{(1+\vartheta)}\left(\mathscr{T} \sqrt{P_{X, t-\Delta t \mid t-\Delta t}}+\sqrt{\mathbf{V}_{t}}\right) \\
& \chi_{-, t-\Delta t}=X_{t \mid t-\Delta t}-\sqrt{(1+\vartheta)}\left(\mathscr{T} \sqrt{P_{X, t-\Delta t \mid t-\Delta t}}+\sqrt{\mathbf{V}_{t}}\right) .
\end{aligned}
$$

The term $\vartheta$ is a scaling constant given by

$$
\vartheta=\mu^{2}(1+\rho)-1
$$

where $\mu, \rho$, and $v$ below are user-specified constants in this paper, with $\mu=0.001, \rho=2$, and $v=2$. Since the values of these constants are not critical in our case, we omit a detailed description for the sake of saving space. Readers are referred to Chow et al. (2007) or Chapter 7 in Haykin et al. (2001) for further details.

4. Transformation of sigma points by way of the measurement function (predictions of measurements):

$\chi_{t \mid t-\Delta t}$ is propagated through the nonlinear measurement function $\mathscr{G}(\cdot)$ :

$$
\mathrm{Y}_{t \mid t-\Delta t}=\mathscr{G}\left(\chi_{t \mid t-\Delta t}\right)
$$

where the dimension of $Y_{t \mid t-\Delta t}$ is $m \times 3$. Then, define the set of weights for the covariance estimates as:

$$
W^{(c)}=\operatorname{diag}\left[\frac{\vartheta}{1+\vartheta}+1-\mu^{2}+v, \frac{1}{2(1+\vartheta)}, \frac{1}{2(1+\vartheta)}\right]_{3 \times 3},
$$


and obtain weights for the mean estimates as follows:

$$
W^{(m)}=\left[\begin{array}{c}
\frac{\vartheta}{1+\vartheta} \\
\frac{1}{2(1+\vartheta)} \\
\frac{1}{2(1+\vartheta)}
\end{array}\right]_{3 \times 1} .
$$

The predicted measurements and associated variance and covariance matrices are computed as follows:

$$
\begin{aligned}
y_{t \mid t-\Delta t} & =\mathrm{Y}_{t \mid t-\Delta t} W^{(m)}, \\
P_{y_{t} \mid t-\Delta t} & =\left[\mathrm{Y}_{t \mid t-\Delta t}-\mathbf{1}_{1 \times 3} \otimes y_{t \mid t-\Delta t}\right] W^{(c)}\left[\mathrm{Y}_{t \mid t-\Delta t}-\mathbf{1}_{1 \times 3} \otimes y_{t \mid t-\Delta t}\right]^{\prime}+\mathscr{S}, \\
P_{X_{t}, y_{t}} & =\left[\chi_{t \mid t-\Delta t}-\mathbf{1}_{1 \times 3} \otimes X_{t \mid t-\Delta t}\right] W^{(c)}\left[\mathrm{Y}_{t \mid t-\Delta t}-\mathbf{1}_{1 \times 3} \otimes y_{t \mid t-\Delta t}\right]^{\prime} .
\end{aligned}
$$

5. Kalman gain and ex-post filtering state update:

With the output from Step 4, actual observations are finally brought in, and the discrepancy between the model's predictions and the actual observations is weighted by a Kalman gain $\Xi_{t-\Delta t}$ to yield ex-post state and covariance estimates as follows:

$$
\begin{aligned}
\Xi_{t-\Delta t} & =P_{X_{t}, y_{t}} P_{y_{t} \mid t-\Delta t}^{-1}, \\
X_{t \mid t} & =X_{t \mid t-\Delta t}+\Xi_{t-\Delta t}\left(y_{t}-y_{t \mid t-\Delta t}\right), \\
P_{X, t \mid t} & =P_{X, t \mid t-\Delta t}-\Xi_{t-\Delta t} P_{y_{t} \mid t-\Delta t} \Xi_{t-\Delta t}^{\prime}, \\
y_{t \mid t} & =\mathscr{G}\left(X_{t \mid t}\right) .
\end{aligned}
$$




\section{References}

Ang, A., V. Bhansali, and Y. Xing (2014). The muni bond spread: Credit, liquidity, and tax. Columbia Business School Research Paper (14-37).

Badaoui, S., L. Cathcart, and L. El-Jahel (2013). Do sovereign credit default swaps represent a clean measure of sovereign default risk? a factor model approach. Journal of Banking \& Finance 37(7), 2392-2407.

Bergstresser, D., R. Cohen, and S. Shenai (2010). Financial guarantors and the 2007-2009 credit crisis. Working papers, Brandeis University.

Bergstresser, D., R. Cohen, and S. Shenai (2015). Skin in the game: The performance of insured and uninsured municipal debt. Working papers, Brandeis University.

Berndt, A., R. Douglas, D. Duffie, M. Ferguson, and D. Schranz (2008). Measuring default risk premia from default swap rates and EDFs. Working papers, Standford University.

Bühler, W. and M. Trapp (2009). Time-varying credit risk and liquidity premia in bond and CDS markets. Technical report, CFR working paper.

Chalmers, J. M. (1998). Default risk cannot explain the muni puzzle: Evidence from municipal bonds that are secured by U.S. Treasury obligations. Review of Financial Studies 11(2), 281-308.

Chen, H., R. Cui, Z. He, and K. Milbradt (2016). Quantifying liquidity and default risks of corporate bonds over the business cycle. Review of Financial Studies, Forthcoming.

Cheridito, P., D. Filipović, and R. L. Kimmel (2007). Market price of risk specifications for affine models: Theory and evidence. Journal of Financial Economics 83(1), 123-170.

Chow, S., E. Ferrer, and J. Nesselroade (2007). An unscented Kalman filter approach to the estimation of nonlinear dynamical systems models. Multivariate Behavorial Research 42(2), 283-321.

Christoffersen, P., C. Dorion, K. Jacobs, and L. Karoui (2014). Nonlinear Kalman filtering in affine term structure models. Management Science 60(9), 2248-2268. 
Chung, S.-L., C.-W. Kao, C. Wu, and C.-Y. Yeh (2015). Counterparty credit risk in the municipal bond market. Journal of Fixed Income 25(1), 7-33.

Downing, C. and F. Zhang (2004). Trading activity and price volatility in the municipal bond market. Journal of Finance 59(2), 899-931.

Driessen, J. (2005). Is default event risk priced in corporate bonds? Review of Financial Studies 18(1), 165-195.

Duffee, G. R. (1999). Estimating the price of default risk. Review of Financial Studies 12(1), 197-226.

Duffee, G. R. and R. H. Stanton (2012). Estimation of dynamic term structure models. Quarterly Journal of Finance 02(02), 1250008.

Ericsson, J. and O. Renault (2006). Liquidity and credit risk. The Journal of Finance 61(5), 2219-2250.

Filipović, D. and A. B. Trolle (2013). The term structure of interbank risk. Journal of Financial Economics 109(3), 707-733.

Green, R. C. (1993). A simple model of the taxable and tax-exempt yield curves. Review of Financial Studies 6(2), 233-264.

Green, R. C., B. Hollifield, and N. Schürhoff (2007). Financial intermediation and the costs of trading in an opaque market. Review of Financial Studies 20(2), 275-314.

Harris, L. E. and M. S. Piwowar (2006). Secondary trading costs in the municipal bond market. The Journal of Finance 61(3), 1361-1397.

Haykin, S. et al. (2001). Kalman Filtering and Neural Networks. Wiley Chichester.

He, Z. and K. Milbradt (2014). Endogenous liquidity and defaultable bonds. Econometrica 82(4), 14431508.

Jarrow, R. A. and S. M. Turnbull (1995). Pricing derivatives on financial securities subject to credit risk. Journal of Finance 50(1), 53-85. 
Lando, D. (1998). On cox processes and credit risky securities. Review of Derivatives research 2(2-3), 99-120.

Longstaff, F. A. (2011). Municipal debt and marginal tax rates: Is there a tax premium in asset prices? Journal of Finance 66(3), 721-751.

Longstaff, F. A., S. Mithal, and E. Neis (2005). Corporate yield spreads: Default risk or liquidity? New evidence from the credit default swap market. Journal of Finance 60(5), 2213-2253.

Moldogaziev, T. T.-u. (2013). The collapse of the municipal bond insurance market: How did we get here and is there life for the monoline industry beyond the great recession? Journal of Public Budgeting, Accounting and Financial Management 25(1), 199.

Ou, S. (2011). Corporate default and recovery rates, 1920-2010. Special Comment, Moody's Investors Service.

Pan, J. and K. Singleton (2008). Default and recovery implicit in the term structure of sovereign CDS spreads. The Journal of Finance 63(5), 2345-2384.

Renick, O. and M. Bonello (2014). Bond insurance then and now: The revival of an industry. Bond Buyer, April 30.

Schwert, M. (2015). Municipal bond liquidity and default risk. Available at SSRN 2408867.

Simon, D. (2006). Optimal State Estimation: Kalman, $H_{\infty}$, and Nonlinear Approaches. WileyInterscience.

Tudela, M., C. Jacoby, and A. Medioli (2015). U.S. municipal bond defaults and recoveries, 1970-2014. Special Comment, Moody’s Investor Service.

Tudela, M., A. Medioli, and A. V. Praagh (2012). U.S. municipal bond defaults and recoveries, 19702011. Special Comment, Moody's Investor Service.

Wang, J., C. Wu, and F. X. Zhang (2008). Liquidity, default, taxes, and yields on municipal bonds. Journal of Banking and Finance 32(6), 1133-1149. 
Wells Fargo (2008). Deterioration of monoline insurance companies and the repercussions for municipal bonds. Technical report.

Yu, J. (2012). Bias in the estimation of the mean reversion parameter in continuous time models. Journal of Econometrics 169(1), 114-122. 
Table 1: Summary statistics of insured and uninsured bonds

This table presents the summary statistics of various characteristics of insured and uninsured bonds used in our regression analysis. Panel (a) shows the first quartile (Q1), median, third quartile (Q3), mean, and standard deviation (Stdev) of the yield, coupon, maturity, offering amount, trade size, and age. Panel (b) shows the average yield and number of observations of insured bonds (insured by Ambac, FGIC, FSA, and MBIA) and uninsured bonds across different ratings: Aaa, Aa1, Aa2, Aa3, A1, A2, A3, Baa1, Baa2, Baa3.

(a) Bond characteristics

\begin{tabular}{lccccc}
\hline & Q1 & Median & Q3 & Mean & Stdev \\
\hline Yield (\%) & 3.00 & 3.42 & 3.75 & 3.39 & 0.67 \\
Coupon (\%) & 3.50 & 4.00 & 5.00 & 3.87 & 1.63 \\
Maturity (years) & 2.42 & 4.58 & 7.35 & 5.60 & 4.63 \\
Offering amount $(\$ 1,000)$ & 921 & 2,620 & 10,300 & 13,700 & 93,200 \\
Trade size $(\$ 1,000)$ & 20 & 50 & 100 & 224 & 1,111 \\
Age (years) & 0.12 & 2.91 & 5.13 & 3.63 & 4.18 \\
\hline
\end{tabular}

(b) Average yields and observations (in parentheses) across ratings

\begin{tabular}{|c|c|c|c|c|c|}
\hline & Ambac & FGIC & FSA & MBIA & Uninsured \\
\hline \multirow[t]{2}{*}{ Aaa } & 3.5 & & 3.39 & 3.46 & 3.29 \\
\hline & $(29,067)$ & & $(91,132)$ & $(64,857)$ & $(71,252)$ \\
\hline \multirow[t]{2}{*}{ Aa1 } & & 3.81 & & & 3.22 \\
\hline & & $(2,659)$ & & & $(25,582)$ \\
\hline \multirow[t]{2}{*}{$\mathrm{Aa} 2$} & & 3.47 & & & 3.21 \\
\hline & & $(5,070)$ & & & $(24,176)$ \\
\hline \multirow[t]{2}{*}{ Aa3 } & & 3.52 & & & 3.34 \\
\hline & & $(10,677)$ & & & $(58,350)$ \\
\hline \multirow[t]{2}{*}{ A1 } & & 3.61 & & & 3.42 \\
\hline & & $(7,275)$ & & & $(23,240)$ \\
\hline \multirow[t]{2}{*}{$\mathrm{A} 2$} & & 3.53 & & & 3.13 \\
\hline & & $(4,357)$ & & & $(1,347)$ \\
\hline \multirow[t]{2}{*}{ A3 } & & 3.43 & & & 3.36 \\
\hline & & $(3,668)$ & & & (768) \\
\hline \multirow[t]{2}{*}{ Baal } & & 3.91 & & & 3.44 \\
\hline & & (722) & & & (295) \\
\hline \multirow[t]{2}{*}{$\mathrm{Baa} 2$} & & 3.59 & & & 3.85 \\
\hline & & (708) & & & (186) \\
\hline \multirow[t]{2}{*}{ Baa3 } & & 3.73 & & & 4.03 \\
\hline & & $(13,755)$ & & & $(1,761)$ \\
\hline
\end{tabular}


Table 2: Panel regressions of municipal bond yields

This table presents the results of the panel regressions of municipal bond yields. The results for bonds with maturities shorter than five years (larger than five years) are shown in columns two to four (five to seven). The results of the regression with issuer CDS premiums are shown in the last column. Robust standard errors adjusted for clustering at the issuer level are in parentheses. ${ }^{*}, * *$, and $* * *$ denote significance at the ten-percent, five-percent, and one-percent level, respectively.

\begin{tabular}{|c|c|c|c|c|c|c|c|}
\hline & \multicolumn{3}{|c|}{ Maturity $<=5$ yrs } & \multicolumn{3}{|c|}{ Maturity $>5$ yrs } & \multirow{2}{*}{ All with CDS } \\
\hline & $\mathrm{A}$ & $\mathrm{Aa}$ & Aaa & $\mathrm{A}$ & $\mathrm{Aa}$ & Aaa & \\
\hline \multirow{3}{*}{ Coupon } & $-0.012 *$ & $-0.032 * * *$ & $-0.03 * * *$ & -0.035 & $-0.027 * *$ & $-0.047 * * *$ & $-0.024 * *$ \\
\hline & $(0.0068)$ & $(0.0089)$ & $(0.0039)$ & $(0.021)$ & $(0.011)$ & $(0.0051)$ & $(0.011)$ \\
\hline & $0.12 * * *$ & $0.084 * * *$ & $0.081 * * *$ & $0.11 * * *$ & $0.1 * * *$ & $0.096 * * *$ & $0.13 * * *$ \\
\hline Maturity & $(0.011)$ & $(0.0087)$ & $(0.0023)$ & $(0.0086)$ & $(0.0048)$ & $(0.0027)$ & $(0.011)$ \\
\hline \multirow{3}{*}{$\operatorname{Ln}($ amount $)$} & $-0.012 * * *$ & -0.0078 & $0.0069^{*}$ & -0.00063 & $0.017 * * *$ & 0.0056 & 0.0021 \\
\hline & $(0.0041)$ & $(0.0059)$ & $(0.0036)$ & $(0.0065)$ & $(0.0049)$ & $(0.0064)$ & $(0.013)$ \\
\hline & $-0.041 * * *$ & $-0.044 * * *$ & $-0.037 * * *$ & 0.0046 & 0.00094 & -0.0015 & $-0.033 * * *$ \\
\hline \multirow[t]{2}{*}{ Ln(tradesize $)$} & $(0.0051)$ & $(0.0067)$ & $(0.0023)$ & $(0.0036)$ & $(0.0017)$ & $(0.002)$ & $(0.0072)$ \\
\hline & $0.007 * * *$ & $0.011 * * *$ & $0.013 * * *$ & -0.00046 & 0.0062 & $0.0096^{* * *}$ & 0.0049 \\
\hline \multirow[t]{2}{*}{ Age } & $(0.00095)$ & $(0.001)$ & $(0.0016)$ & $(0.0011)$ & $(0.0045)$ & $(0.0024)$ & $(0.0047)$ \\
\hline & $-0.11 * * *$ & $-0.036 * *$ & $-0.043^{*}$ & $-0.1 * * *$ & -0.037 & -0.037 & $-0.078 * * *$ \\
\hline \multirow[t]{2}{*}{ Insured } & $(0.025)$ & $(0.017)$ & $(0.023)$ & $(0.028)$ & $(0.027)$ & $(0.041)$ & $(0.027)$ \\
\hline & $0.000032 * * *$ & 0.000017 & $0.000072 * * *$ & $0.000074 * * *$ & $0.000068 * * *$ & $0.00012 * * *$ & 0.000025 \\
\hline \multirow[t]{2}{*}{ Insurer 5yr CDS } & $(0.0000077)$ & $(0.000012)$ & $(0.000013)$ & $(0.0000097)$ & $(0.0000075)$ & $(0.000022)$ & $(0.000016)$ \\
\hline & & & & & & & $0.01 * * *$ \\
\hline Issuer 5yr CDS & & & & & & & $(0.0015)$ \\
\hline Time FE & yes & yes & yes & yes & yes & yes & yes \\
\hline Issuer FE & yes & yes & yes & yes & yes & yes & yes \\
\hline Adj. $R^{2}$ & 0.61 & 0.62 & 0.61 & 0.87 & 0.84 & 0.86 & 0.73 \\
\hline Obs & 21,930 & 73,147 & 129,718 & 16,512 & 45,623 & 110,406 & 12,692 \\
\hline Issuers & 975 & 1,388 & 5,700 & 426 & 716 & 3,791 & 22 \\
\hline
\end{tabular}


Table 3: Correlation among the CDS premia of the four insurers and five issuers

This table summarizes the correlations among the first order differences of five-year CDS premia of the four monolines: Ambac, FGIC, FSA, and MBIA and the five issuers: the State of California (CA), the State of Illinois (IL), the State of Massachusetts (MA), the State of New Jersey (NJ), and the City of New York (NYC). P-values for testing the hypothesis of zero correlation are presented in parentheses. *, **, and *** denote significance at the ten-percent, five-percent, and one-percent level, respectively.

\begin{tabular}{|c|c|c|c|c|c|}
\hline & CA & IL & MA & NJ & NYC \\
\hline \multirow[t]{2}{*}{ Ambac } & $0.201^{* * *}$ & 0.102 & $0.115^{*}$ & 0.114 & 0.074 \\
\hline & $(0.00)$ & $(0.16)$ & $(0.07)$ & $(0.10)$ & $(0.26)$ \\
\hline \multirow[t]{2}{*}{ FGIC } & 0.055 & 0.053 & 0.016 & 0.078 & -0.028 \\
\hline & $(0.40)$ & $(0.47)$ & $(0.81)$ & $(0.26)$ & $(0.67)$ \\
\hline \multirow[t]{2}{*}{ FSA } & $0.204^{* * *}$ & $0.194^{* * *}$ & 0.094 & 0.107 & 0.043 \\
\hline & $(0.00)$ & $(0.01)$ & $(0.14)$ & $(0.13)$ & $(0.51)$ \\
\hline \multirow[t]{2}{*}{ MBIA } & $0.196^{* * *}$ & 0.099 & $0.115^{*}$ & 0.043 & 0.020 \\
\hline & $(0.00)$ & $(0.17)$ & $(0.07)$ & $(0.54)$ & $(0.76)$ \\
\hline
\end{tabular}


Table 4: Parameter estimates of the monoline default intensities

This table presents the parameter estimates of the default intensities, $\lambda_{m, t}$, of the four monolines: Ambac, FGIC, FSA, and MBIA. The standard errors are presented in parentheses. "ave VR" is the variance ratio averaged across CDS maturities, where the variance ratio is defined as one minus the ratio of the variance of pricing errors to the variance of actual CDS premiums. "rel RMSE" is the ratio of the root mean squared CDS pricing error to the sample average of actual CDS premiums. "rel RMSE" is in percentages. *, **, and *** denote significance at the ten-percent, five-percent, and one-percent level, respectively.

\begin{tabular}{|c|c|c|c|c|c|c|c|c|c|c|}
\hline & $\alpha_{m}$ & $\beta_{m}$ & $\sigma_{m}$ & $\alpha_{m}^{P}$ & $\beta_{m}^{P}$ & $c_{0}$ & $c_{1}$ & $w_{m}$ & ave VR & rel RMSE \% \\
\hline \multirow{2}{*}{ Ambac } & 0.001 & $0.049^{* * *}$ & $0.271^{* * *}$ & 0.003 & $-3.301^{* * *}$ & 0.001 & $0.163^{* * *}$ & $0.912^{* * *}$ & \multirow{2}{*}{1.00} & \multirow{2}{*}{6.01} \\
\hline & $(0.00)$ & $(0.00)$ & $(0.01)$ & $(0.01)$ & $(0.78)$ & $(0.00)$ & $(0.03)$ & $(0.03)$ & & \\
\hline \multirow{2}{*}{ FGIC } & -0.000 & $0.121^{* * *}$ & $0.530^{* * *}$ & 0.003 & $-2.467^{* * *}$ & 0.001 & $1.040^{*}$ & $0.971^{* * *}$ & \multirow{2}{*}{0.97} & \multirow{2}{*}{30.42} \\
\hline & $(0.00)$ & $(0.01)$ & $(0.01)$ & $(0.02)$ & $(0.72)$ & $(0.00)$ & $(0.56)$ & $(0.03)$ & & \\
\hline \multirow{2}{*}{ FSA } & 0.002 & $0.041^{* * *}$ & $0.305^{* * *}$ & 0.041 & -1.231 & 0.000 & $0.031^{* * *}$ & $0.577^{* * *}$ & \multirow{2}{*}{0.99} & \multirow{2}{*}{8.87} \\
\hline & $(0.00)$ & $(0.01)$ & $(0.01)$ & $(0.03)$ & (1.94) & $(0.00)$ & $(0.01)$ & $(0.05)$ & & \\
\hline \multirow{2}{*}{ MBIA } & 0.001 & $0.064^{* * *}$ & $0.298^{* * *}$ & 0.008 & $-4.449^{* * *}$ & 0.004 & $0.622^{* * *}$ & $0.797^{* * *}$ & \multirow{2}{*}{0.99} & \multirow{2}{*}{11.37} \\
\hline & $(0.00)$ & $(0.00)$ & $(0.01)$ & $(0.02)$ & $(0.71)$ & $(0.00)$ & $(0.17)$ & $(0.02)$ & & \\
\hline
\end{tabular}


Table 5: Summary of the parameter estimates and fitting performance of the municipal bond pricing model

This table summarizes the parameter estimates and fitting performance of the municipal bond pricing model for 61 issuers. "Q1" ("Q3") is the 25\% (75\%) percentile of the sample. "(in)", “(un)", and "(all)" represent results of insured bonds, uninsured bonds, and all bonds, respectively. "VR" denotes the variance ratio, defined as one minus the ratio of the variance of pricing errors to the variance of actual bond prices. "rel RMSE" is the ratio of the root mean squared pricing error to the sample average of actual bond prices. "rel RMSE" is in percentages.

\begin{tabular}{lcccc}
\hline & Q1 & Median & Q3 & Mean \\
\hline$\alpha_{i}$ & -0.000 & -0.000 & 0.000 & 0.000 \\
$\beta_{i}$ & -0.142 & -0.058 & 0.059 & -0.071 \\
$\sigma_{i}$ & 0.047 & 0.089 & 0.188 & 0.126 \\
$\alpha_{i}^{P}$ & 0.002 & 0.021 & 0.100 & 0.077 \\
$\beta_{i}^{P}$ & 7.819 & 10.833 & 21.363 & 16.059 \\
$c_{4}$ & -0.001 & 0.000 & 0.005 & 0.005 \\
$c_{5}$ & -0.034 & 0.003 & 0.309 & 0.429 \\
$c_{6}$ & -0.007 & -0.001 & 0.005 & -0.002 \\
$c_{2}^{i n}$ & 0.003 & 0.006 & 0.007 & 0.004 \\
$c_{3}^{i n}$ & -0.125 & -0.006 & 0.070 & 0.096 \\
$c_{7}^{i n}$ & 0.829 & 3.169 & 14.688 & 31.087 \\
$c_{2}^{\text {un }}$ & 0.000 & 0.005 & 0.007 & 0.004 \\
$c_{3}^{\text {un }}$ & -0.059 & 0.064 & 0.659 & 0.251 \\
$c_{7}^{\text {un }}$ & 0.257 & 3.807 & 15.785 & 32.896 \\
$\delta$ & 0.001 & 0.483 & 0.611 & 0.369 \\
$\operatorname{VR}($ all) & 0.965 & 0.988 & 0.994 & 0.970 \\
VR(in) & 0.969 & 0.981 & 0.994 & 0.977 \\
VR(un) & 0.942 & 0.986 & 0.996 & 0.899 \\
rel RMSE(all) \% & 0.371 & 0.531 & 0.723 & 0.598 \\
rel RMSE(in) $\%$ & 0.310 & 0.467 & 0.613 & 0.486 \\
rel RMSE(un) \% & 0.302 & 0.447 & 0.769 & 0.674 \\
\hline
\end{tabular}


Table 6: Summary of the average yield components of 61 issuers

This table summarizes the sample averages (from July 2007 to June 2008) of different yield components of 61 issuers' insured and uninsured bonds. "Q1" ("Q3") is the 25\% (75\%) percentile of the sample. This yield decomposition is done by applying their individual calibrated municipal bond pricing models to a hypothetical bond, which has a semi-annual coupon rate of $5.25 \%$ and a maturity of 4.2 years. For the insured bond, we consider the default component, liquidity component, and default+insurance component (both FSA and MBIA). For the uninsured bond, we consider the default component and liquidity component. All numbers in the table are in percentages.

\begin{tabular}{|c|c|c|c|c|c|c|}
\hline \multicolumn{2}{|c|}{ Groups } & \multirow{2}{*}{$\begin{array}{c}\text { Default } \\
0.039\end{array}$} & \multirow{2}{*}{$\begin{array}{c}\begin{array}{c}\text { Def+Ins } \\
\text { (FSA) }\end{array} \\
0.004\end{array}$} & \multirow{2}{*}{$\begin{array}{c}\begin{array}{r}\text { Def+Ins } \\
(\mathrm{MBIA})\end{array} \\
0.006\end{array}$} & \multirow{2}{*}{$\begin{array}{c}\text { Insured Liq } \\
0.904\end{array}$} & \multirow{2}{*}{$\begin{array}{c}\begin{array}{c}\text { Uninsured } \\
\text { Liq }\end{array} \\
0.442\end{array}$} \\
\hline \multirow{4}{*}{$\begin{array}{l}\text { All } \\
\text { (61 issuers) }\end{array}$} & Q1 & & & & & \\
\hline & Median & 0.355 & 0.037 & 0.081 & 0.983 & 0.871 \\
\hline & Q3 & 0.830 & 0.088 & 0.178 & 1.052 & 1.130 \\
\hline & Mean & 0.526 & 0.056 & 0.112 & 0.987 & 0.706 \\
\hline \multirow{4}{*}{$\begin{array}{l}\text { States } \\
\text { (17 issuers) }\end{array}$} & Q1 & 0.038 & 0.003 & 0.006 & 0.956 & 0.870 \\
\hline & Median & 0.189 & 0.026 & 0.061 & 1.024 & 1.074 \\
\hline & Q3 & 0.386 & 0.045 & 0.099 & 1.104 & 1.248 \\
\hline & Mean & 0.321 & 0.038 & 0.079 & 1.031 & 1.021 \\
\hline \multirow{4}{*}{$\begin{array}{l}\text { Cities } \\
\text { (17 issuers) }\end{array}$} & Q1 & 0.287 & 0.031 & 0.069 & 0.865 & 0.144 \\
\hline & Median & 0.531 & 0.061 & 0.119 & 0.952 & 0.655 \\
\hline & Q3 & 0.922 & 0.097 & 0.198 & 1.026 & 1.043 \\
\hline & Mean & 0.689 & 0.069 & 0.134 & 0.961 & 0.483 \\
\hline \multirow{4}{*}{$\begin{array}{l}\text { Sch. Dist. } \\
\text { (17 issuers) }\end{array}$} & Q1 & 0.039 & 0.004 & 0.008 & 0.898 & 0.215 \\
\hline & Median & 0.355 & 0.041 & 0.088 & 0.959 & 0.730 \\
\hline & Q3 & 0.946 & 0.091 & 0.191 & 1.044 & 0.994 \\
\hline & Mean & 0.627 & 0.068 & 0.141 & 0.985 & 0.601 \\
\hline
\end{tabular}


Table 7: Summary of the average default and liquidity sub-components of 61 issuers

This table summarizes the sample averages (from July 2007 to June 2008) of the default and liquidity components in yields of 61 issuers' insured and uninsured bonds. "Q1" ("Q3") is the 25\% (75\%) percentile of the sample. This yield decomposition is done by applying their individual calibrated municipal bond pricing models to a hypothetical bond. The bond has a semi-annual coupon rate of 5.25\% and a maturity of 4.2 years. For the default component which is common for insured and uninsured bonds, we consider total default, pure default, and liquidity-driven default. For the liquidity component in insured and uninsured bonds, we consider the total liquidity, pure liquidity, and default-driven liquidity. All numbers in the table are in percentage.

\begin{tabular}{|c|c|c|c|c|c|c|c|c|c|c|}
\hline \multirow{2}{*}{\multicolumn{2}{|c|}{ Groups }} & \multicolumn{3}{|c|}{ Default } & \multicolumn{3}{|c|}{ Insured Liquidity } & \multicolumn{3}{|c|}{ Uninsured Liquidity } \\
\hline & & Total & Pure & Liq & Total & Pure & Def & Total & Pure & Def \\
\hline \multirow{4}{*}{$\begin{array}{l}\text { All } \\
\text { (61 issuers) }\end{array}$} & Q1 & 0.039 & 0.040 & -0.004 & 0.904 & 0.372 & 0.229 & 0.442 & 0.055 & 0.114 \\
\hline & Median & 0.355 & 0.249 & 0.001 & 0.983 & 0.668 & 0.369 & 0.871 & 0.551 & 0.286 \\
\hline & Q3 & 0.830 & 0.769 & 0.072 & 1.052 & 0.767 & 0.629 & 1.130 & 0.880 & 0.570 \\
\hline & Mean & 0.526 & 0.484 & 0.042 & 0.987 & 0.471 & 0.516 & 0.706 & 0.500 & 0.206 \\
\hline \multirow{4}{*}{$\begin{array}{l}\text { States } \\
\text { (17 issuers) }\end{array}$} & Q1 & 0.038 & 0.017 & -0.003 & 0.956 & 0.419 & 0.217 & 0.870 & 0.482 & 0.118 \\
\hline & Median & 0.189 & 0.084 & 0.005 & 1.024 & 0.670 & 0.370 & 1.074 & 0.879 & 0.286 \\
\hline & Q3 & 0.386 & 0.335 & 0.072 & 1.104 & 0.788 & 0.666 & 1.247 & 1.109 & 0.388 \\
\hline & Mean & 0.321 & 0.266 & 0.055 & 1.031 & 0.417 & 0.614 & 1.021 & 0.977 & 0.044 \\
\hline \multirow{4}{*}{$\begin{array}{l}\text { Cities } \\
\text { (17 issuers) }\end{array}$} & Q1 & 0.287 & 0.242 & -0.047 & 0.865 & 0.410 & 0.179 & 0.144 & -0.106 & 0.082 \\
\hline & Median & 0.531 & 0.524 & -0.000 & 0.952 & 0.644 & 0.345 & 0.655 & 0.198 & 0.202 \\
\hline & Q3 & 0.922 & 0.893 & 0.041 & 1.026 & 0.831 & 0.585 & 1.043 & 0.799 & 0.577 \\
\hline & Mean & 0.689 & 0.719 & -0.030 & 0.961 & 0.554 & 0.406 & 0.483 & 0.236 & 0.247 \\
\hline \multirow{4}{*}{$\begin{array}{l}\text { Sch. Dist. } \\
\text { (17 issuers) }\end{array}$} & Q1 & 0.039 & 0.101 & -0.000 & 0.898 & 0.255 & 0.244 & 0.215 & 0.055 & 0.114 \\
\hline & Median & 0.355 & 0.264 & 0.001 & 0.959 & 0.671 & 0.430 & 0.730 & 0.302 & 0.353 \\
\hline & Q3 & 0.946 & 0.945 & 0.080 & 1.044 & 0.731 & 0.679 & 0.994 & 0.731 & 0.573 \\
\hline & Mean & 0.627 & 0.541 & 0.086 & 0.985 & 0.429 & 0.555 & 0.601 & 0.402 & 0.199 \\
\hline
\end{tabular}


Table 8: Specification tests of the municipal bond pricing model

This table reports the parameter estimates of the regressions specified in (24) and (25). The estimation is performed using QML. The standard errors adjusted for non-normality of the residuals are reported in parentheses. *, **, and *** denote significance at the ten-percent, five-percent, and one-percent level, respectively.

\begin{tabular}{|c|c|c|c|c|c|c|c|}
\hline \multirow{2}{*}{$\begin{array}{l}\text { Dependent } \\
\text { variable }\end{array}$} & \multicolumn{4}{|c|}{ Explanatory variables } & \multirow[b]{2}{*}{$b_{0}$} & \multirow[b]{2}{*}{$\sqrt{\Omega}$} & \multirow[b]{2}{*}{$\rho$} \\
\hline & $b_{1}$ & $b_{2}$ & $b_{3}$ & $b_{4}$ & & & \\
\hline \multirow[t]{2}{*}{$\zeta_{i, t}$} & $-0.05^{* * *}$ & $-0.10^{* * *}$ & $-0.17^{* * *}$ & N.A. & 0.01 & $0.71^{* * *}$ & $0.19^{* * *}$ \\
\hline & $(0.01)$ & $(0.02)$ & $(0.01)$ & & $(0.02)$ & $(0.02)$ & $(0.03)$ \\
\hline \multirow[t]{2}{*}{$\left|\zeta_{i, t}\right|$} & $0.03^{* *}$ & $0.04^{* * *}$ & $0.08^{* * *}$ & 0.03 & $0.42^{* * *}$ & $0.50^{* * *}$ & $0.06^{* * *}$ \\
\hline & $(0.01)$ & $(0.01)$ & $(0.01)$ & $(0.20)$ & $(0.02)$ & $(0.01)$ & $(0.02)$ \\
\hline
\end{tabular}


Table 9: Correlation among the liquidity factor, the monoline default intensities, and the issuer default intensities

This table summarizes the correlations among the first order differences of $\hat{l}, \hat{\lambda}_{m}^{\prime}$, and $\hat{h}_{i}$. P-values for testing the hypothesis of zero correlation are presented in parentheses. *,**, and *** denote significance at the ten-percent, five-percent, and one-percent level, respectively.

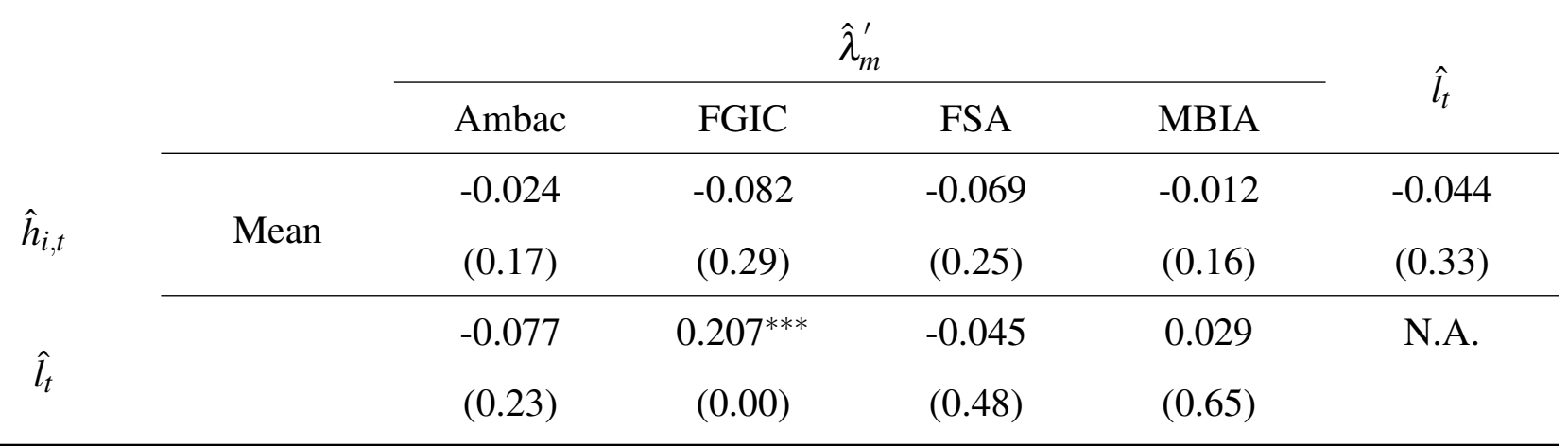

Figure 1: Monoline CDS premiums

This figure shows the dynamics of five-year CDS premiums of the four monolines, Ambac, FGIC, FSA, and MBIA, from January 2007 to December 2008.

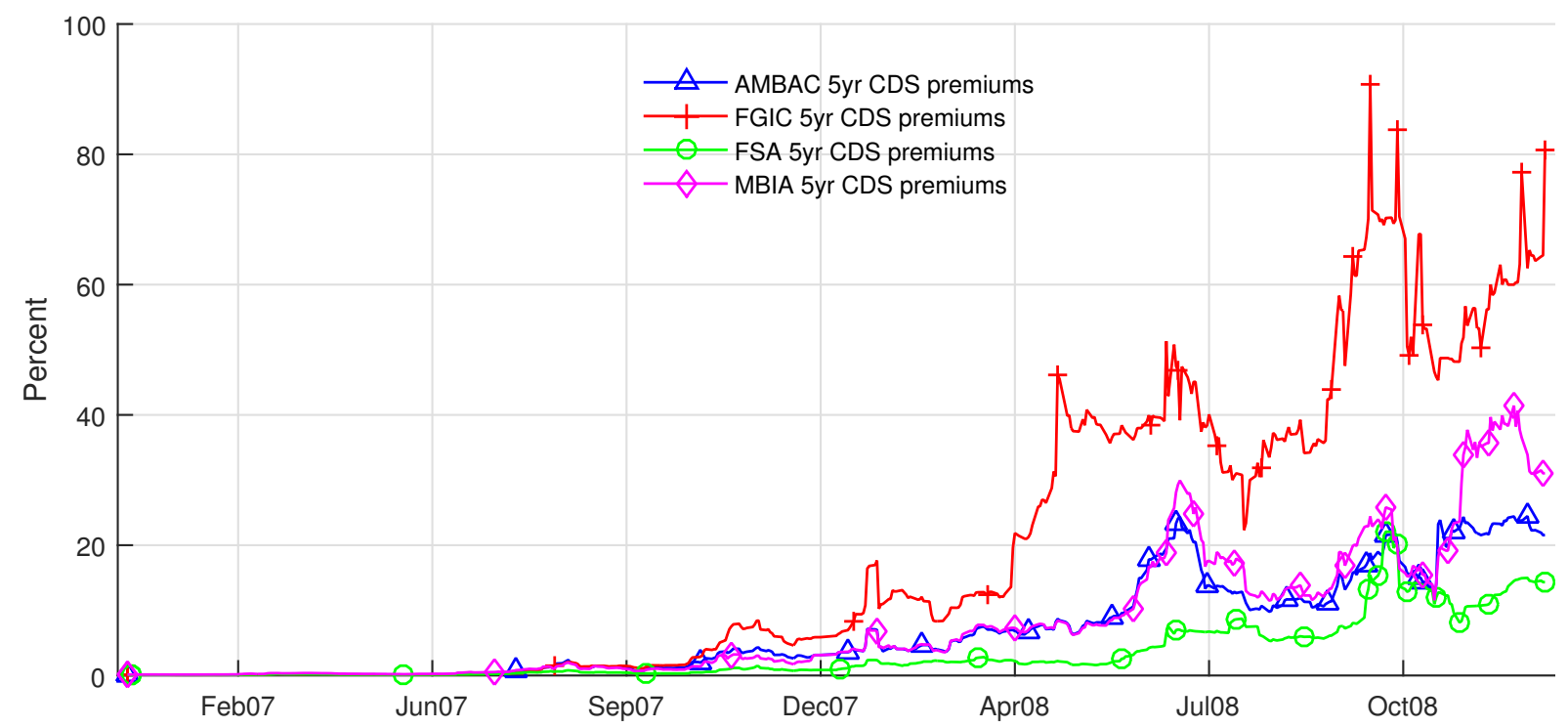


Table 10: Summary of the Simulation Results

This table summarizes the comparison between true and estimated parameters as well as the errors in estimates of the state variable. Median, Mean, and Standard Deviation (Std) are reported. "RMSE" is the root mean squared state estimation error (the difference between the filtered state variable $\hat{h}_{i}$ and the true state varialbe $h_{i}$ ); "rel RMSE" is the root mean squared state estimation relative error (state estimation error divided by $h_{i}$ ); "RMSE" is basis point (bp) and "rel RMSE" is in percentage. The mean and standard deviation of the estimates are based on 500 Monte Carlo simulations. In each simulation, 213 points of $h_{i}$ (matching the dates we have in our sample period) are simulated. Given the true parameters, $l$, and $\lambda_{m}$, the prices of six coupon (5\%, semiannual) bonds with maturities of one, four, eight, and 10 years for insured bonds, and two and five years for uninsured bonds are computed at every point in time.

\begin{tabular}{lcccc}
\hline & True & Median & Mean & Std \\
\hline$\alpha_{i}$ & -0.001 & -0.001 & -0.001 & 0.000 \\
$\beta_{i}$ & -0.058 & -0.058 & -0.058 & 0.000 \\
$\sigma_{i}$ & 0.089 & 0.086 & 0.086 & 0.005 \\
$\alpha_{i}^{P} / \beta_{i}^{P}$ & 0.002 & 0.002 & 0.003 & 0.018 \\
$\beta_{i}^{P}$ & 10.83 & 9.93 & 9.90 & 4.99 \\
$c_{4}$ & 0.001 & 0.001 & 0.001 & 0.000 \\
$c_{5}$ & 0.003 & 0.003 & 0.003 & 0.000 \\
$c_{6}$ & -0.001 & -0.001 & -0.001 & 0.000 \\
$c_{2}^{i n}$ & 0.006 & 0.006 & 0.006 & 0.000 \\
$c_{3}^{i n}$ & -0.006 & -0.006 & -0.006 & 0.000 \\
$c_{7}^{i n}$ & 3.169 & 3.413 & 3.468 & 0.457 \\
$c_{2}^{\text {un }}$ & 0.005 & 0.005 & 0.005 & 0.000 \\
$c_{3}^{\text {un }}$ & 0.064 & 0.064 & 0.064 & 0.001 \\
$c_{7}^{\text {un }}$ & 3.807 & 4.103 & 4.169 & 0.554 \\
$\delta$ & 0.483 & 0.446 & 0.438 & 0.068 \\
$\mathrm{RMSE}_{\mathrm{rel} \mathrm{RMSE}(\%)}$ & 3.130 & 3.615 & 2.724 \\
\hline & & 9.505 & 11.073 \\
\hline
\end{tabular}


Figure 2: Relation between bond yield and bond age

This figure plots the average bond yield against bond age separately for short-term bonds (maturity shorter than 5 years), long-term bonds (maturity longer than 5 years), and all bonds.

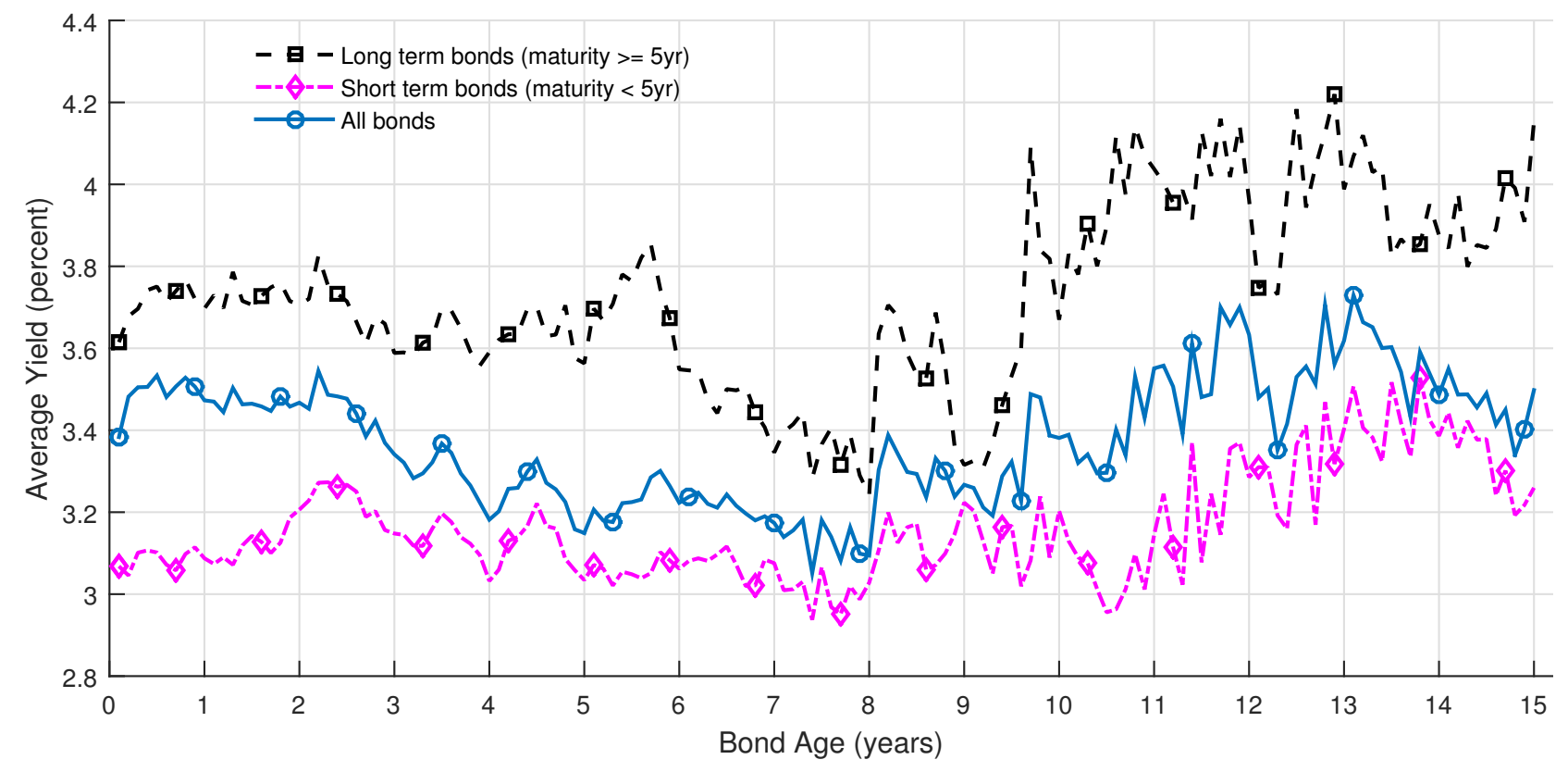

Figure 3: Liquidity spreads and the aggregate liquidity factor

This figure presents the dynamics of the short-term liquidity spread, long-term liquidity spread, and filtered liquidity factor $l_{t}$ from July 2007 to June 2008.

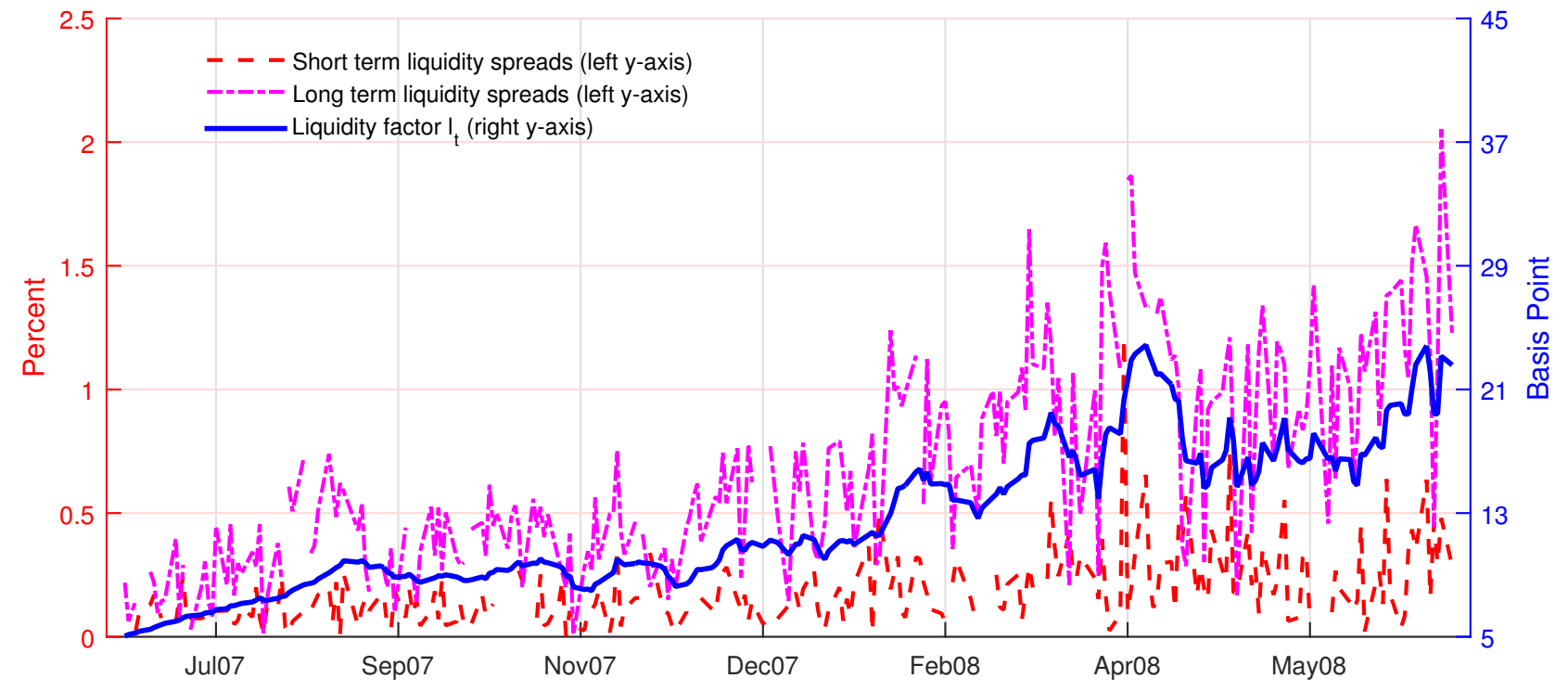


Figure 4: Monoline CDS pricing performance

This figure compares the model CDS premiums and the actual CDS premiums for the four monolines.

(a) Ambac

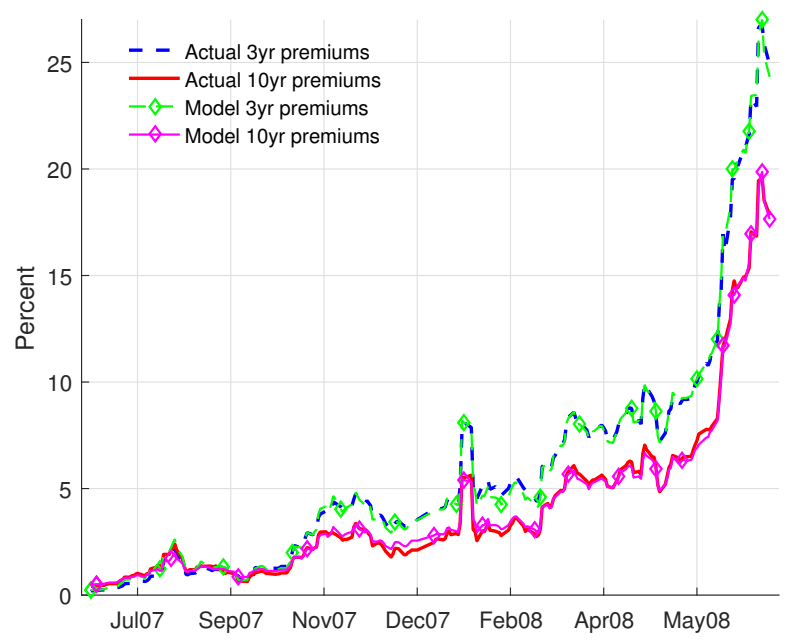

(c) FSA

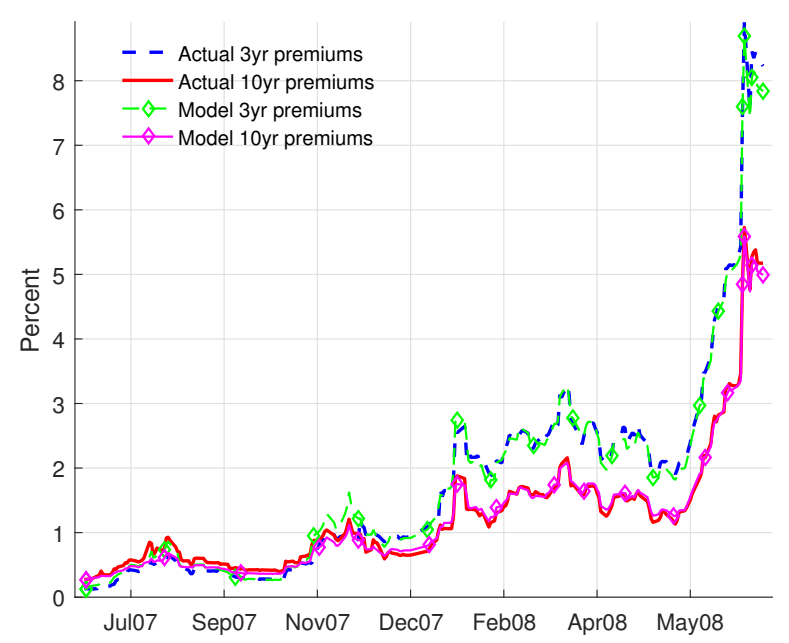

(b) FGIC

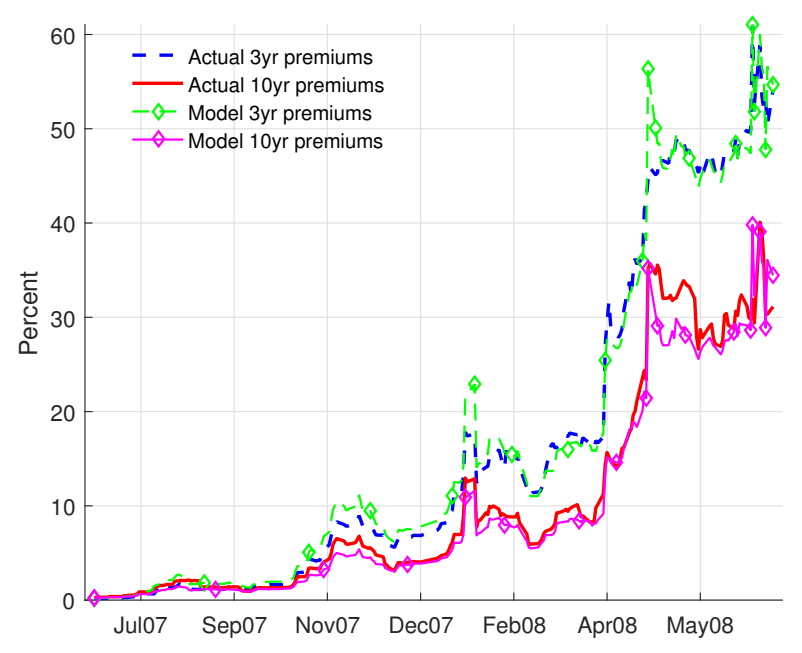

(d) MBIA

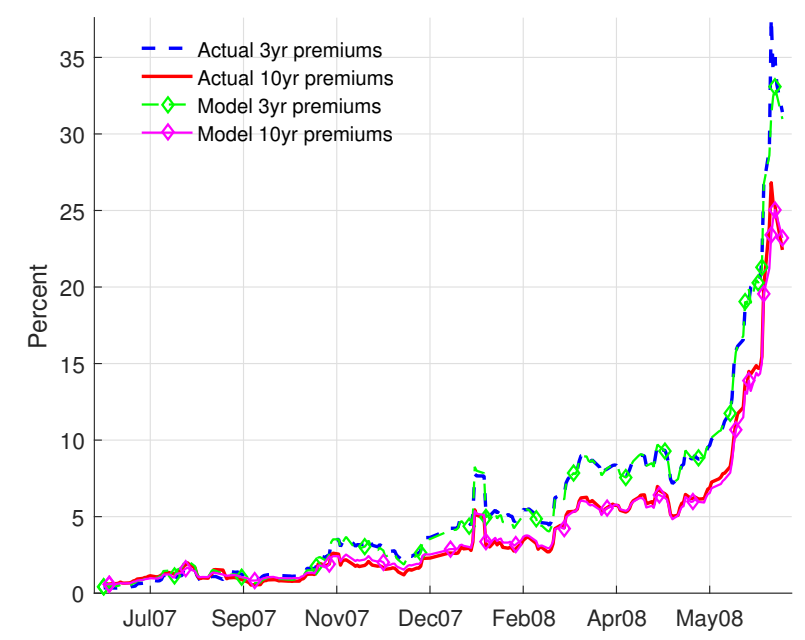


Figure 5: Yield decomposition of insured and uninsured bonds

This figure plots the median of yield components across the 61 issuers from July 2007 to June 2008. This yield decomposition is done by applying each issuer's individual calibrated municipal bond pricing model to a hypothetical bond, which has a semi-annual coupon rate of $5.25 \%$ and a maturity of 4.2 years. For the insured bond, we consider the liquidity component and default+insurance component (both FSA and MBIA). For the uninsured bond, we consider the liquidity component and default component.

(a) Yield components of MBIA-insured and uninsured bonds

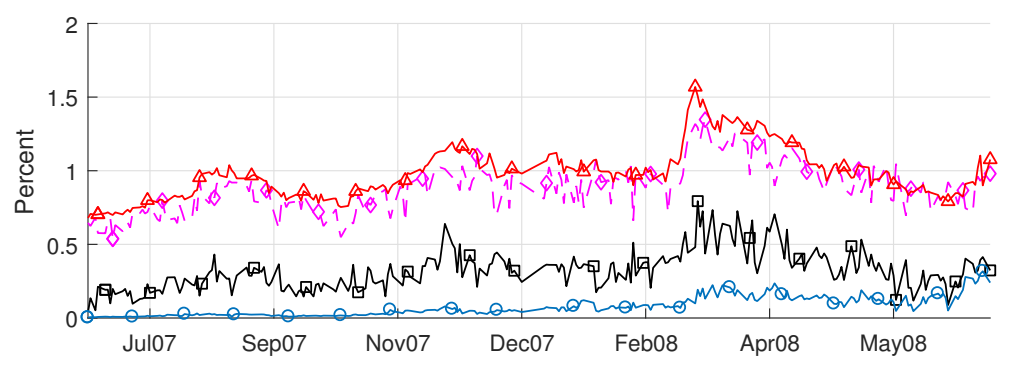

$\square-$ default(un) $-\diamond-$ liquidity(un) —- default and insurance(in) $\triangle-$ liquidity(in)

(c) Yield comparison (MBIA-insured vs uninsured)

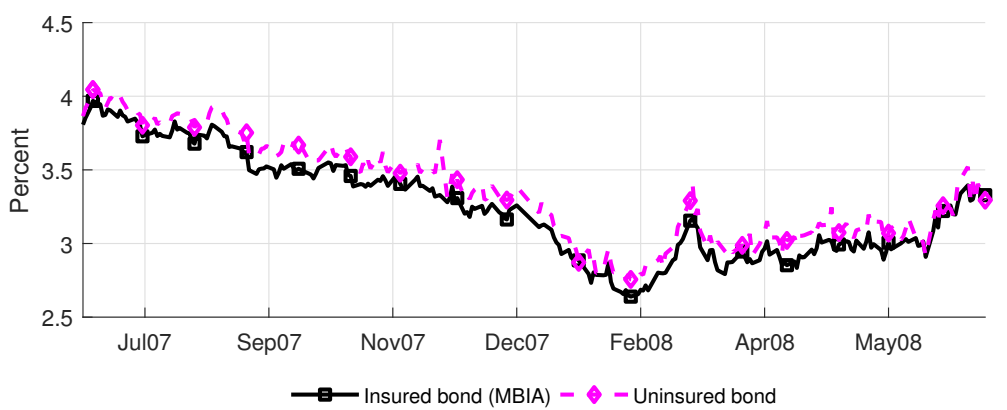

(e) Yield difference (uninsured minus MBIA-insured)

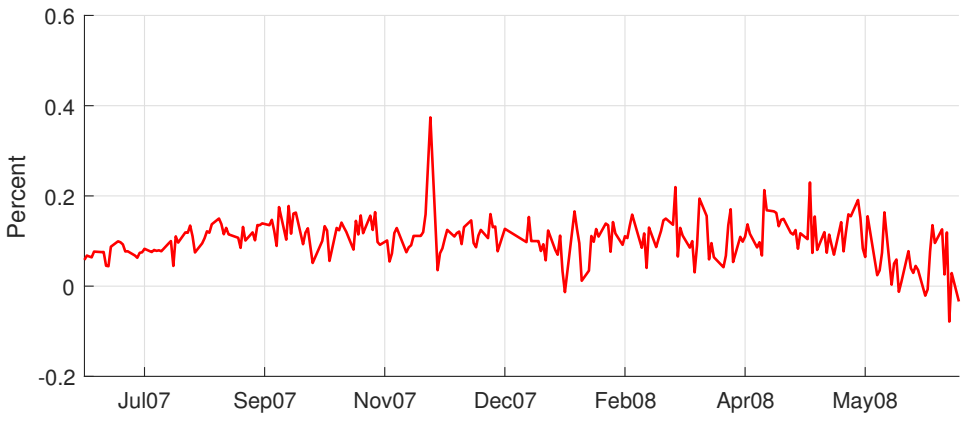

(b) Yield components of FSA-insured and uninsured bonds

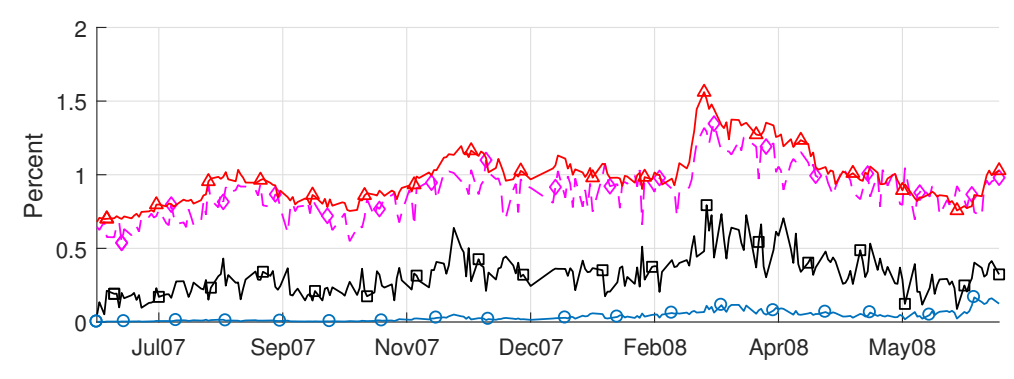

$\square-$ default(un) $-\diamond-$ liquidity(un) -0 - default and insurance(in) $\triangle-$ liquidity(in)

(d) Yield comparison (FSA-insured vs uninsured)

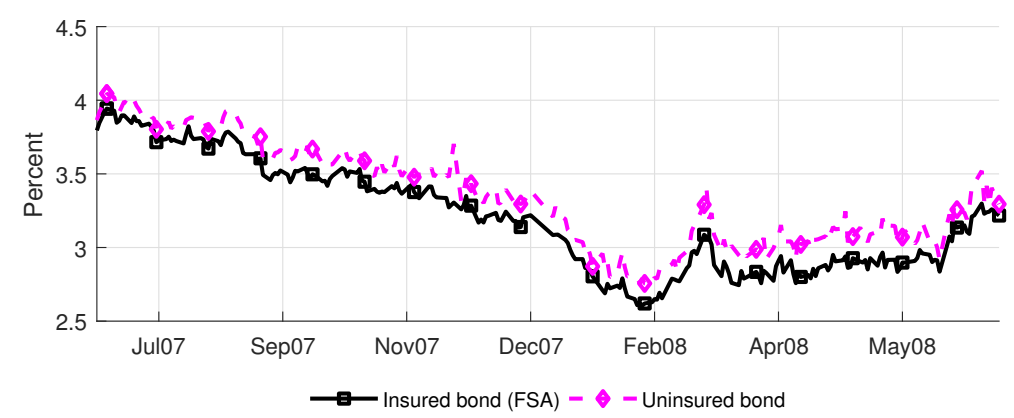

(f) Yield difference (uninsured minus FSA-insured)

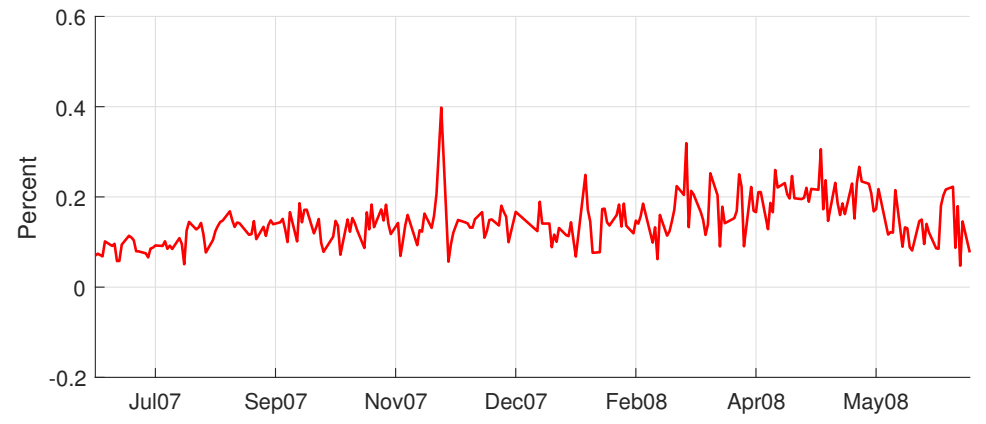


Figure 6: Yield decomposition of insured and uninsured bonds

This figure plots the median of default and liquidity components in yields across the 61 issuers from July 2007 to June 2008. This yield decomposition is done by applying each issuer's individual calibrated municipal bond pricing model to a hypothetical bond, which has a semi-annual coupon rate of 5.25\% and a maturity of 4.2 years. For the default component which is common for insured and uninsured bonds, we consider the pure default and liquidity-driven default. For the liquidity component in insured and uninsured bonds, we consider the pure liquidity and default-driven liquidity.

(a) Default component decomposition

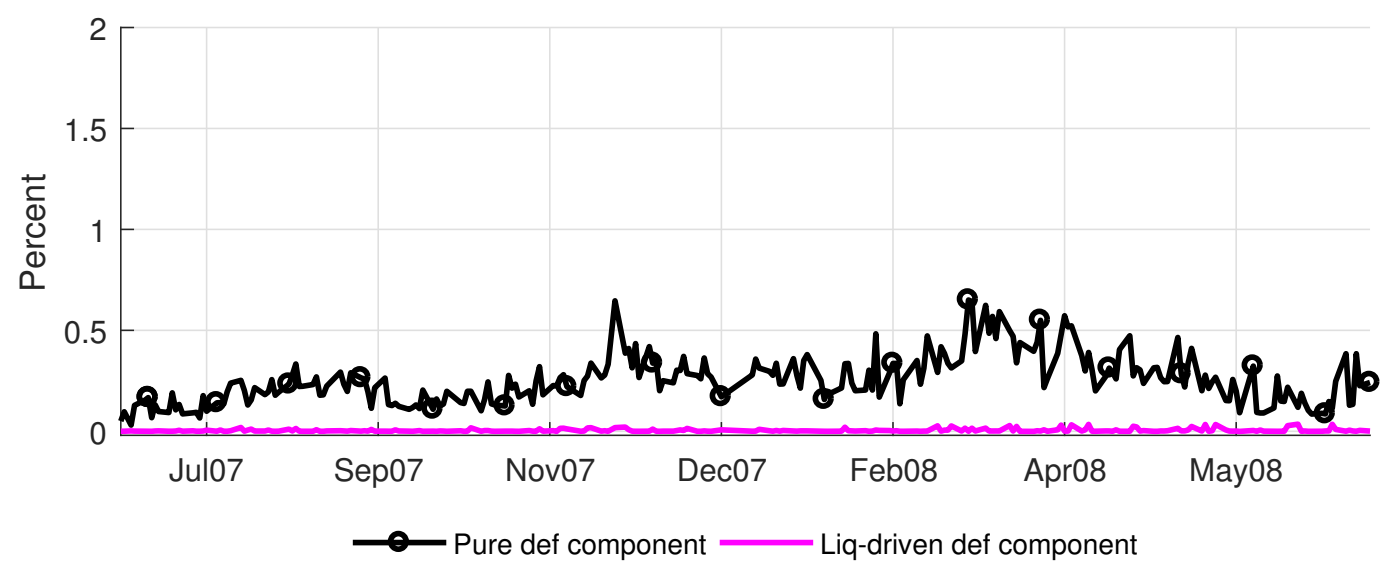

(b) Insured bond liquidity component decomposition

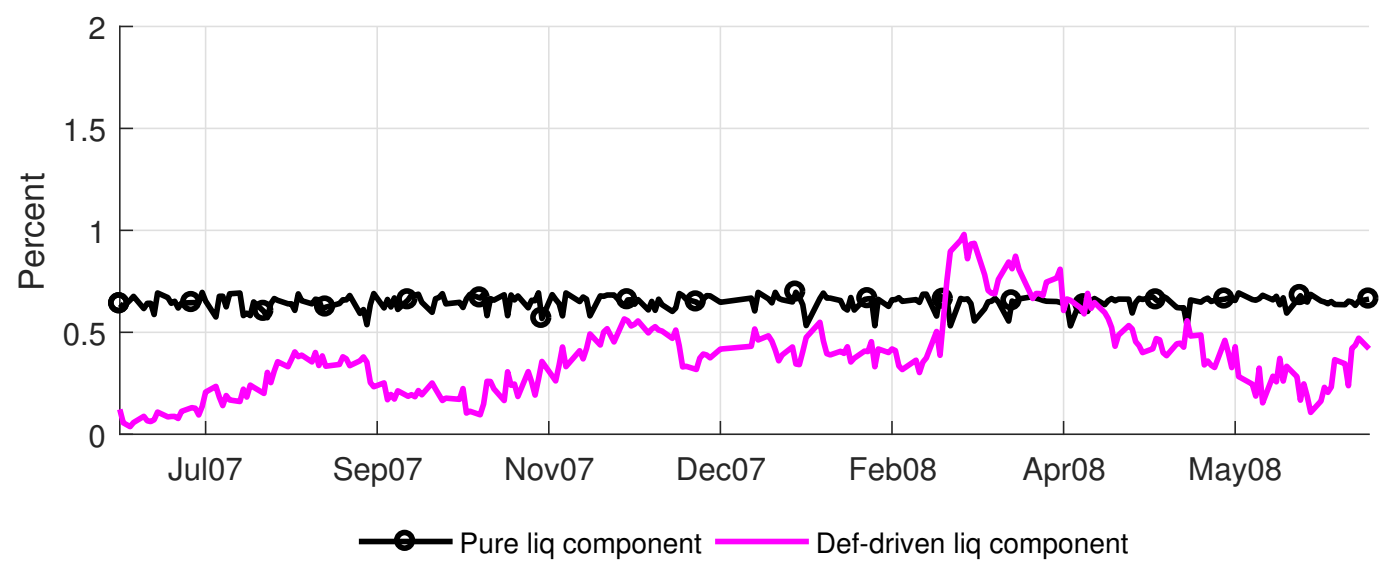

(c) Uninsured bond liquidity component decomposition

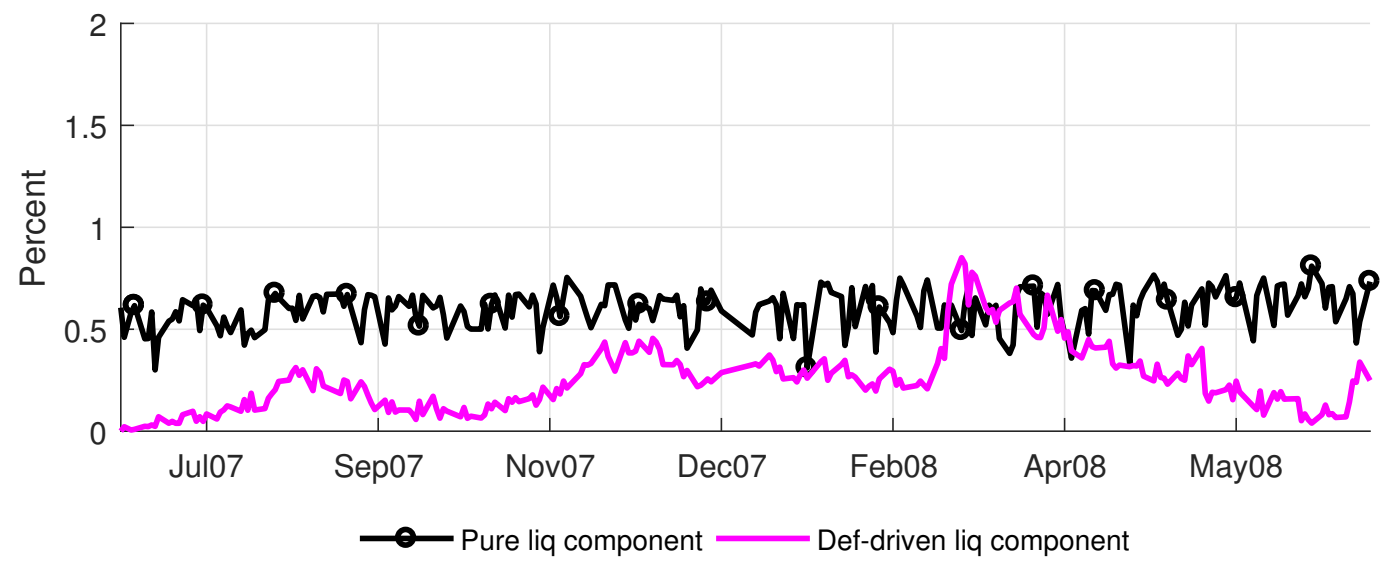


Figure 7: Sensitivity of bond prices to the recovery rate

This figure shows the sensitivity of bond prices to the recovery rate. The sensitivity is calculated by varying $\delta$ from 0 to $90 \%$ while the value of $(1-\delta) h_{i}$ is fixed at 9.4 bps for coupon (5\%, semiannual) bonds with maturities of one, four, and eight years. Panel (a) shows the results of insured bonds (FSA), and Panel (b) shows the results of uninsured bonds.

(a) Insured bonds (FSA)

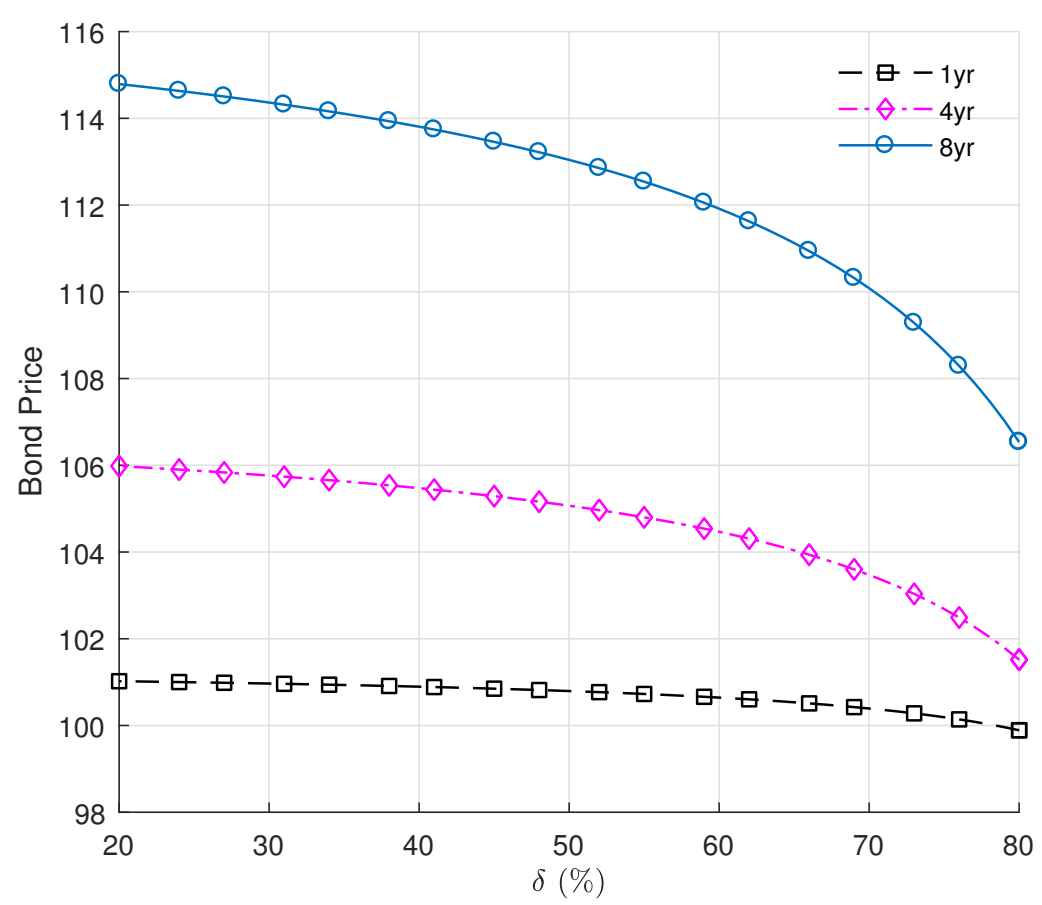

(b) Uninsured bonds

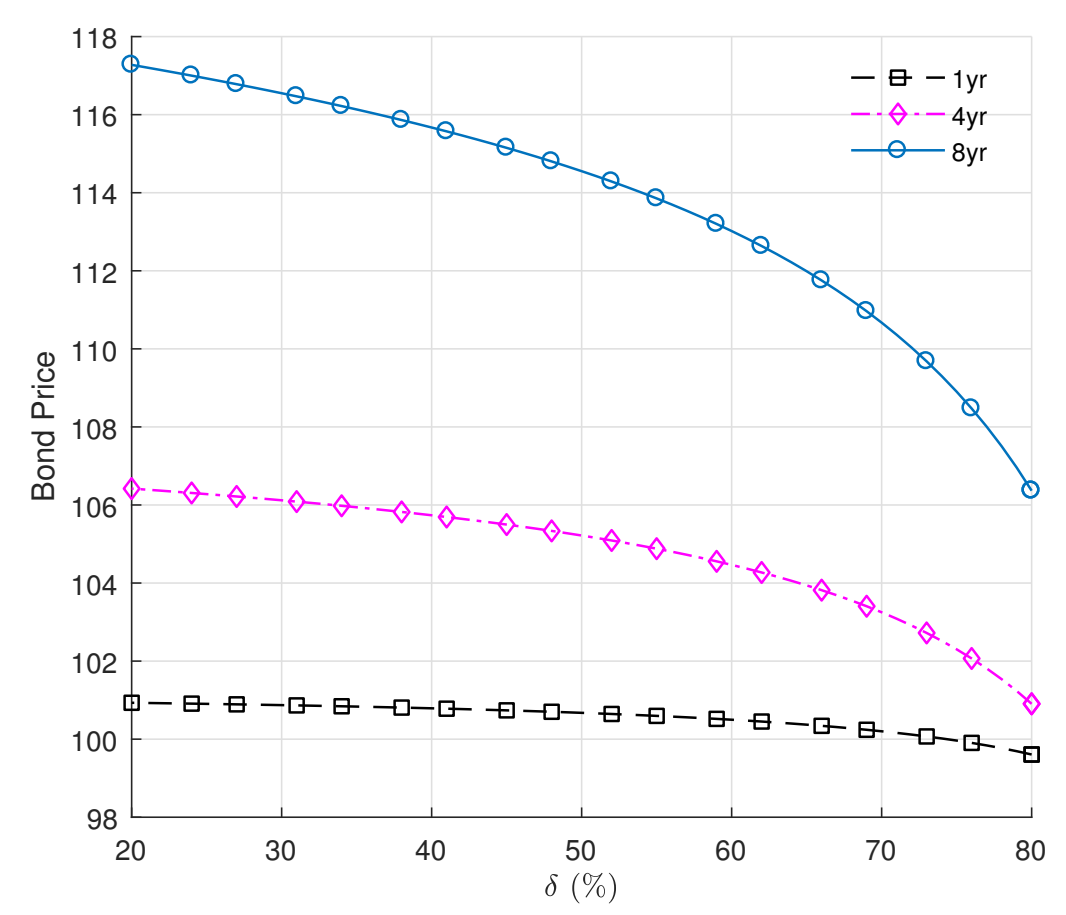


Figure 8: Partial derivative of the insured coupon bond price with respect to the recovery rate

This figure shows the partial derivative of the insured bond (FSA) price, which is a function of $\delta$ and $(1-\delta) h_{i}$ instead of $\delta$ and $h_{i}$, with respect to the recovery rate $\delta$. The partial derivative is calculated by varying $\sigma_{i}$ (left, upper panel), $\alpha_{i}$ (right, upper panel), $\beta_{i}$ (left, middle panel), $(1-\delta) h_{i}$ (right, middle panel), and $\delta$ (left, lower panel) for coupon (5\%, semiannual) bonds with maturities of one, four, and eight years. The fixed parameters are displayed in the title of each panel.
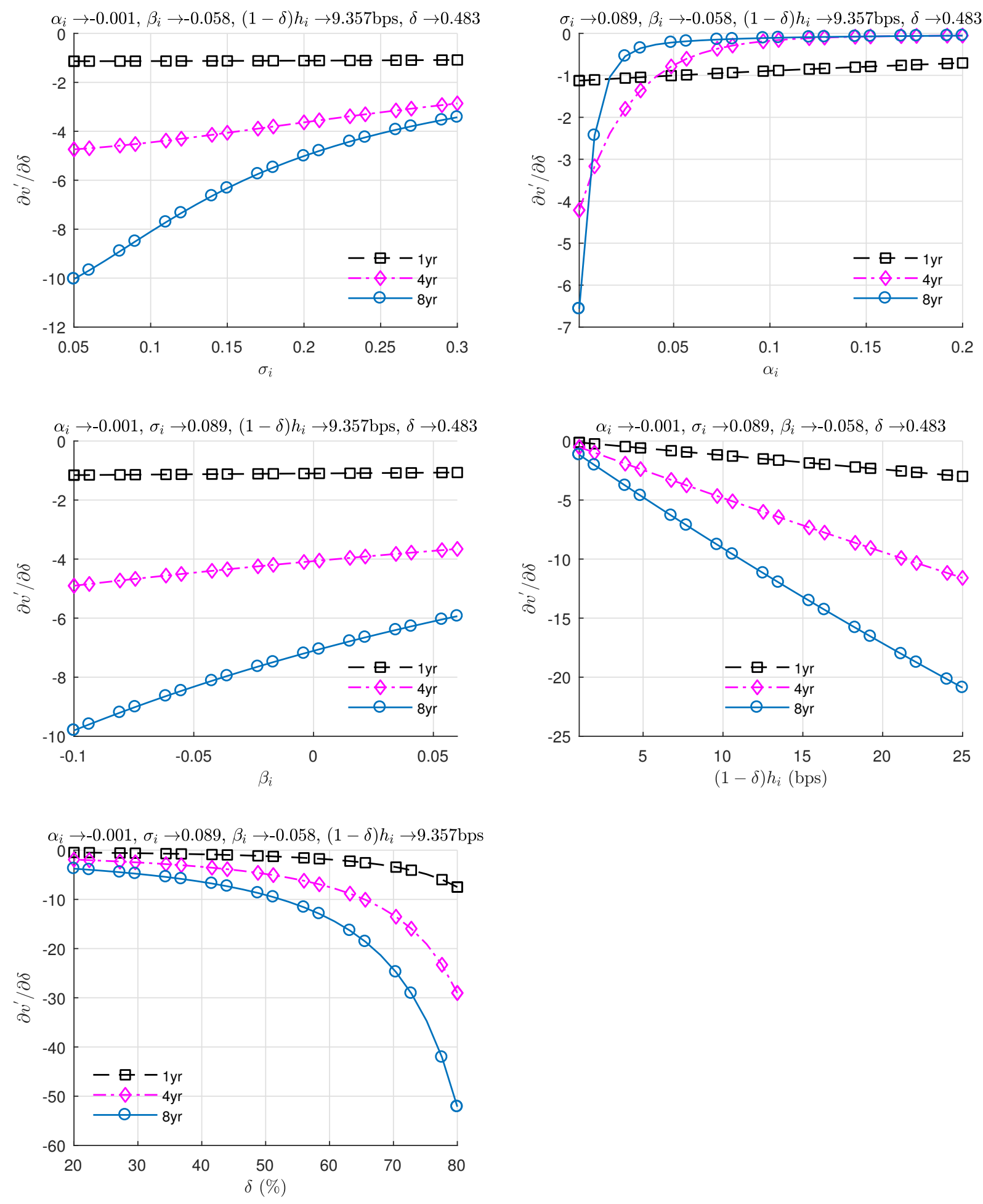
Figure 9: Partial derivative of the uninsured coupon bond price with respect to the recovery rate

This figure shows the partial derivative of the uninsured bond price, which is a function of $\delta$ and $(1-\delta) h_{i}$ instead of $\delta$ and $h_{i}$, with respect to the recovery rate $\delta$. The partial derivative is calculated by varying $\sigma_{i}$ (left, upper panel), $\alpha_{i}$ (right, upper panel), $\beta_{i}$ (left, middle panel), $(1-\delta) h_{i}$ (right, middle panel), and $\delta$ (left, lower panel) for coupon (5\%, semiannual) bonds with maturities of one, four, and eight years. The fixed parameters are displayed in the title of each panel.
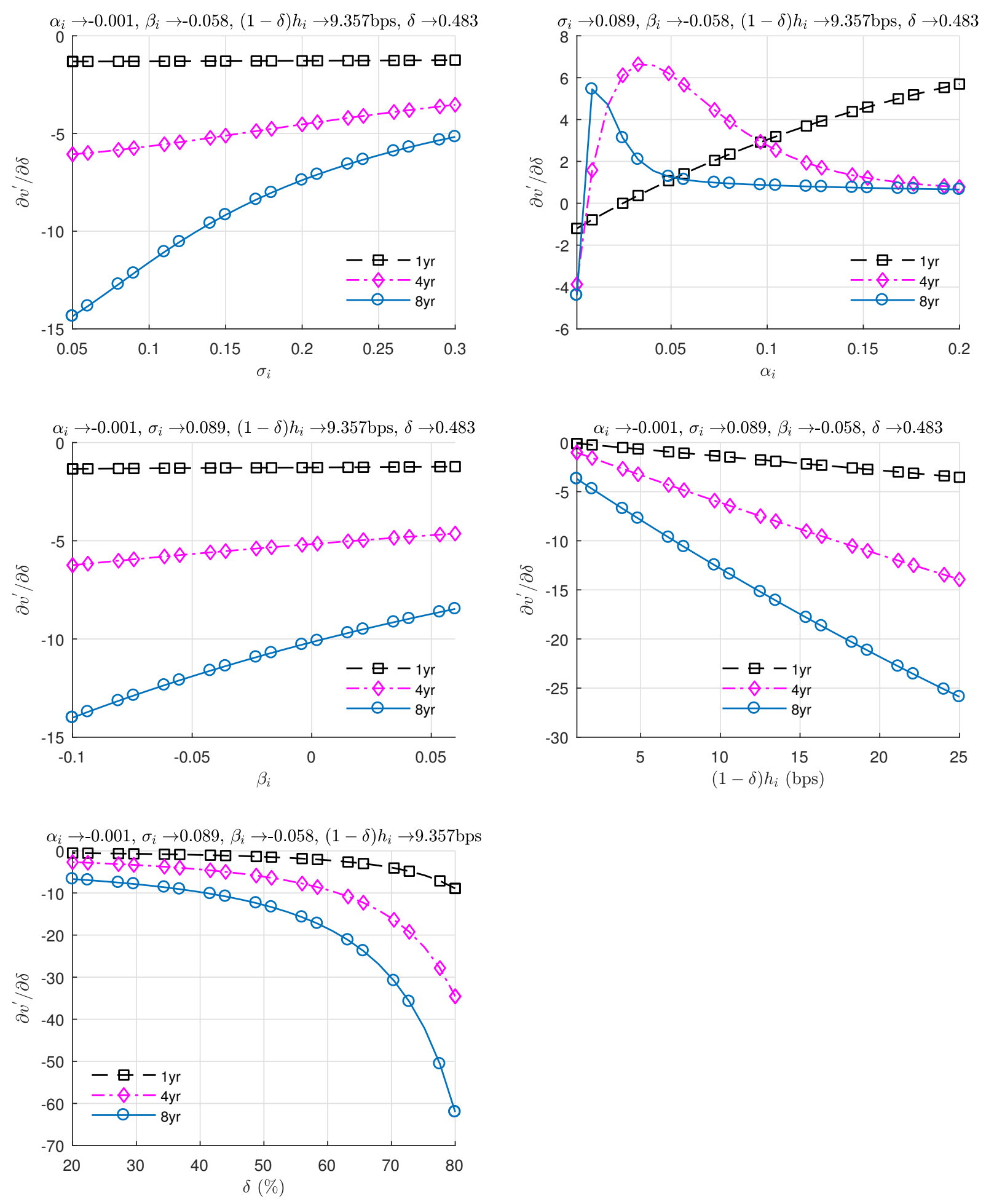